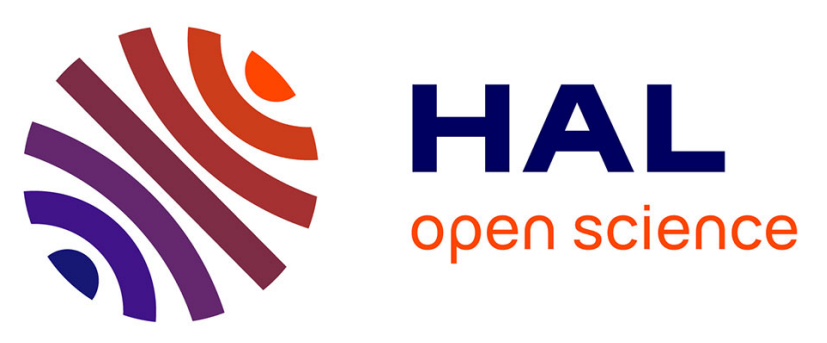

\title{
Nanoparticles of Low-Valence Vanadium Oxyhydroxides: Reaction Mechanisms and Polymorphism Control by Low-Temperature Aqueous Chemistry
}

Julie Besnardiere, Xavier Petrissans, François Ribot, Valérie Briois, Christine Surcin, Mathieu Morcrette, Valérie Buissette, Thierry Le Mercier, Sophie Cassaignon, David Portehault

\section{To cite this version:}

Julie Besnardiere, Xavier Petrissans, François Ribot, Valérie Briois, Christine Surcin, et al.. Nanoparticles of Low-Valence Vanadium Oxyhydroxides: Reaction Mechanisms and Polymorphism Control by Low-Temperature Aqueous Chemistry. Inorganic Chemistry, 2016, 55 (21), pp.11502 - 11512. 10.1021/acs.inorgchem.6b02059 . hal-01395197

\section{HAL Id: hal-01395197 https://hal.sorbonne-universite.fr/hal-01395197}

Submitted on 10 Nov 2016

HAL is a multi-disciplinary open access archive for the deposit and dissemination of scientific research documents, whether they are published or not. The documents may come from teaching and research institutions in France or abroad, or from public or private research centers.
L'archive ouverte pluridisciplinaire HAL, est destinée au dépôt et à la diffusion de documents scientifiques de niveau recherche, publiés ou non, émanant des établissements d'enseignement et de recherche français ou étrangers, des laboratoires publics ou privés. 


\section{Nanoparticles of low valence vanadium oxyhydroxides: reaction mechanisms and}

\section{polymorphism control by low temperature aqueous chemistry}

Julie Besnardiere, ${ }^{1}$ Xavier Petrissans, ${ }^{2}$ François Ribot, ${ }^{1}$ Valérie Briois, ${ }^{3}$ Christine Surcin, ${ }^{4}$ Mathieu Morcrette, ${ }^{4}$ Valérie Buissette, ${ }^{5}$ Thierry Le Mercier, ${ }^{5}$ Sophie Cassaignon, ${ }^{1}$ David Portehault $^{1, *}$

${ }^{1}$ Sorbonne Universités UPMC Univ Paris 06 - CNRS - Collège de France, UMR 7574 Chimie de la Matière Condensée de Paris Collège de France, 11 place Marcelin Berthelot, 75231 Paris Cedex 05, France

${ }^{2}$ Institut de Recherche de Chimie Paris, UMR CNRS 8247, Chimie ParisTech, 11 rue Pierre et Marie Curie, 75005 Paris, France

${ }^{3}$ Synchrotron SOLEIL, L'Orme des Merisiers, Saint-Aubin - BP 48, Gif-sur-Yvette F-91192, France.

${ }^{4}$ Université de Picardie Jules Verne - CNRS - Réseau sur le Stockage Electrochimique de l'Energie (RS2E), UMR 7314 Laboratoire de Réactivité des Solides, 33 Rue Saint Leu, 80039 Amiens Cedex (France).

${ }^{5}$ Solvay, Centre de Recherches d'Aubervilliers, 52 rue de la Haie-Coq, 93308 Aubervilliers Cedex, France.

Corresponding author: david.portehault@upmc.fr

\section{KEYWORDS:}

Vanadium oxides

Nanoparticles

Aqueous chemistry

Soft chemistry

X-ray Absorption Spectroscopy 


\title{
SYNOPSIS TOC
}

An aqueous synthetic route at $95{ }^{\circ} \mathrm{C}$ yields selectively three scarcely reported vanadium $+\mathrm{IV}$ oxyhydroxides as nanoparticles with the smallest sizes reported so far. Formation mechanisms are addressed and highlight the extreme $\mathrm{pH}$-sensitivity of the synthetic routes.

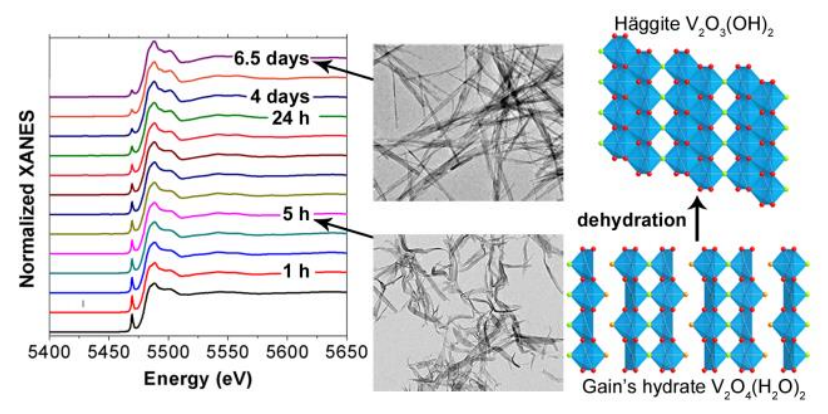

\begin{abstract}
An aqueous synthetic route at $95{ }^{\circ} \mathrm{C}$ is developed to reach selectively three scarcely reported vanadium oxyhydroxides. Häggite, Duttonite and Gain's hydrate are obtained as nanowires, nanorods and nanoribbons, with sizes one order of magnitude smaller than previously reported. X-ray absorption spectroscopy provides evidences that vanadium in these phases is $\mathrm{V}^{+\mathrm{IV}}$. Combined with FTIR, XRD and electron microscopy, it yields the first insights into formation mechanisms, especially for Häggite and Gain's hydrate. This study opens the way for further investigations of the properties of novel $\mathrm{V}^{+\mathrm{IV}}$ (oxyhydr)oxides nanostructures.
\end{abstract}




\section{INTRODUCTION}

Vanadium oxides and oxyhydroxides offer a well-furnished toolbox that contains a wide variety of compositions, structures, redox states, etc. This results in a large diversity of electrical, optical and intercalation properties, which can be implemented in many applications, especially in the fields of oxidative catalysis ${ }^{1-14}\left(e . g\right.$. production of sulfuric acid $^{1}$ and maleic acid ${ }^{15}$ ) and energy. ${ }^{16-27}$ Several current technologies of redox flow batteries, ${ }^{16} \mathrm{Li}$ ion or Na-ion batteries, ${ }^{17-27}$ smart thermochromics, ${ }^{28}$ electrochromic windows ${ }^{29}$ and thermoelectric devices ${ }^{30}$ are based on vanadium oxy-compounds. This profusion of applications relates directly to the various crystal structures and structure-property relationships. ${ }^{29,30}$ Especially, reduced phases incorporating $\mathrm{V}^{\mathrm{III}}$ and/or $\mathrm{V}^{\mathrm{IV}}$ species exhibit electrical properties of utmost importance, with e.g. a metal-to-insulator (MIT) transition ${ }^{28,30}$ involved in smart systems. Mastering the crystallographic structure permits to adjust the electron transport properties which are crucial for electrochemical storage and for thermochromic behaviors based on the MIT. However, while only one allotrope of $\mathrm{V}_{2} \mathrm{O}_{5}$ is known, a hundred of reduced phases have been reported. This striking contrast points out the ambivalence of low valence vanadium oxides: they provide a unique range of compounds to adjust properties but materials chemists must face the challenge of selective elaboration with controlled structure, oxidation state and morphology in order to understand and efficiently use these properties. ${ }^{17-27,30,31}$

This report is focused on two vanadium oxyhydroxides little studied in the literature. On one side, Duttonite $\mathrm{V}^{\mathrm{IV}} \mathrm{O}(\mathrm{OH})_{2}$ (Figure 1) is made of chains of distorted octahedra $\mathrm{VO}_{2}(\mathrm{OH})_{4}$ sharing edges. Chains are connected together by the $\mathrm{OH}$ corners with alternating long $\mathrm{V}-\mathrm{O}$ and short $\mathrm{V}=\mathrm{O}$ bonds. Duttonite was discovered in natural ores ${ }^{32,33}$ and reported thrice $^{34-36}$ from hydrothermal routes. Duttonite's nano-/micro-structure has not been reported so far. On the other side, Häggite (Figure 2) is made of corrugated sheets linked by H bonds. 
The sheets are made of double chains of edge-sharing octahedra. The chains are connected by oxo corners in V-O-V bridges consisting in two short V-O bonds. Häggite is naturally present in some ores but only 3 synthetic routes are known: ${ }^{37-39}$ (1) reduction of $\mathrm{NH}_{4} \mathrm{VO}_{3}$ by wood or lignite under hydrothermal conditions for few days, ${ }^{38}$ (2) Pt-catalyzed reduction of $\mathrm{V}_{2} \mathrm{O}_{5}$ by $\mathrm{H}_{2}$ at $150{ }^{\circ} \mathrm{C},{ }^{39}$ and (3) hydrothermal oxidation of a preformed $\mathrm{V}(\mathrm{OH})_{2} \mathrm{NH}_{2}$ complex. ${ }^{37}$ This last study from Wu et al. is the only one reporting Häggite's microstructure, consisting in $200 \mathrm{~nm}$ wide ribbons with micrometric length. ${ }^{37}$ Häggite's composition was described as $\mathrm{V}^{\mathrm{IV}} \mathrm{V}^{\mathrm{III}} \mathrm{O}_{2}(\mathrm{OH})_{3}$ until $\mathrm{Wu}$ et al.'s work proposed $\mathrm{V}^{\mathrm{IV}}{ }_{2} \mathrm{O}_{3}(\mathrm{OH})_{2}$. Due to the difficulty of selective synthesis, the properties of both Häggite and Duttonite are mostly unreported, except for Häggite that was recently shown to possess a semiconductor-insulator transition at $66 \mathrm{~K}$ with abrupt changes of its conductivity and magnetic response. ${ }^{37}$

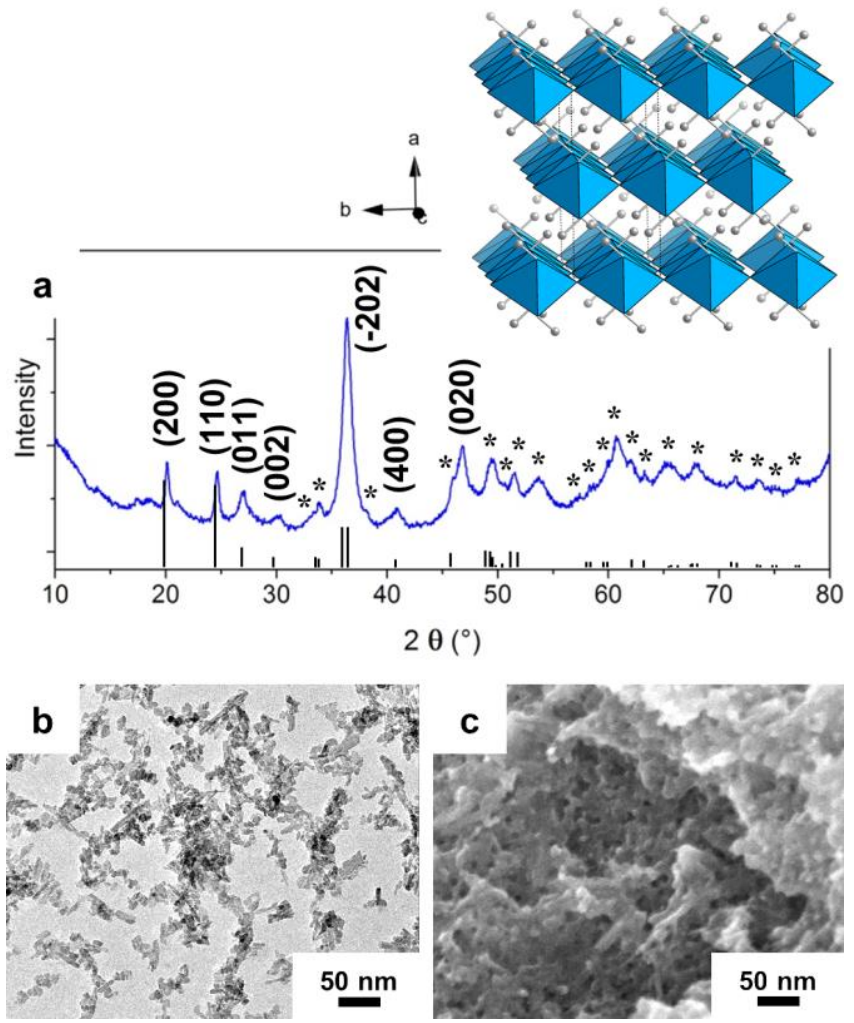

Figure 1. Structure and morphology of Duttonite nanorods obtained at pH 4.0. (a) Powder XRD pattern indexed (*) according to the 01-072-1230 JCPDS card. (b) TEM and (c) FESEM pictures of Duttonite nanorods. 

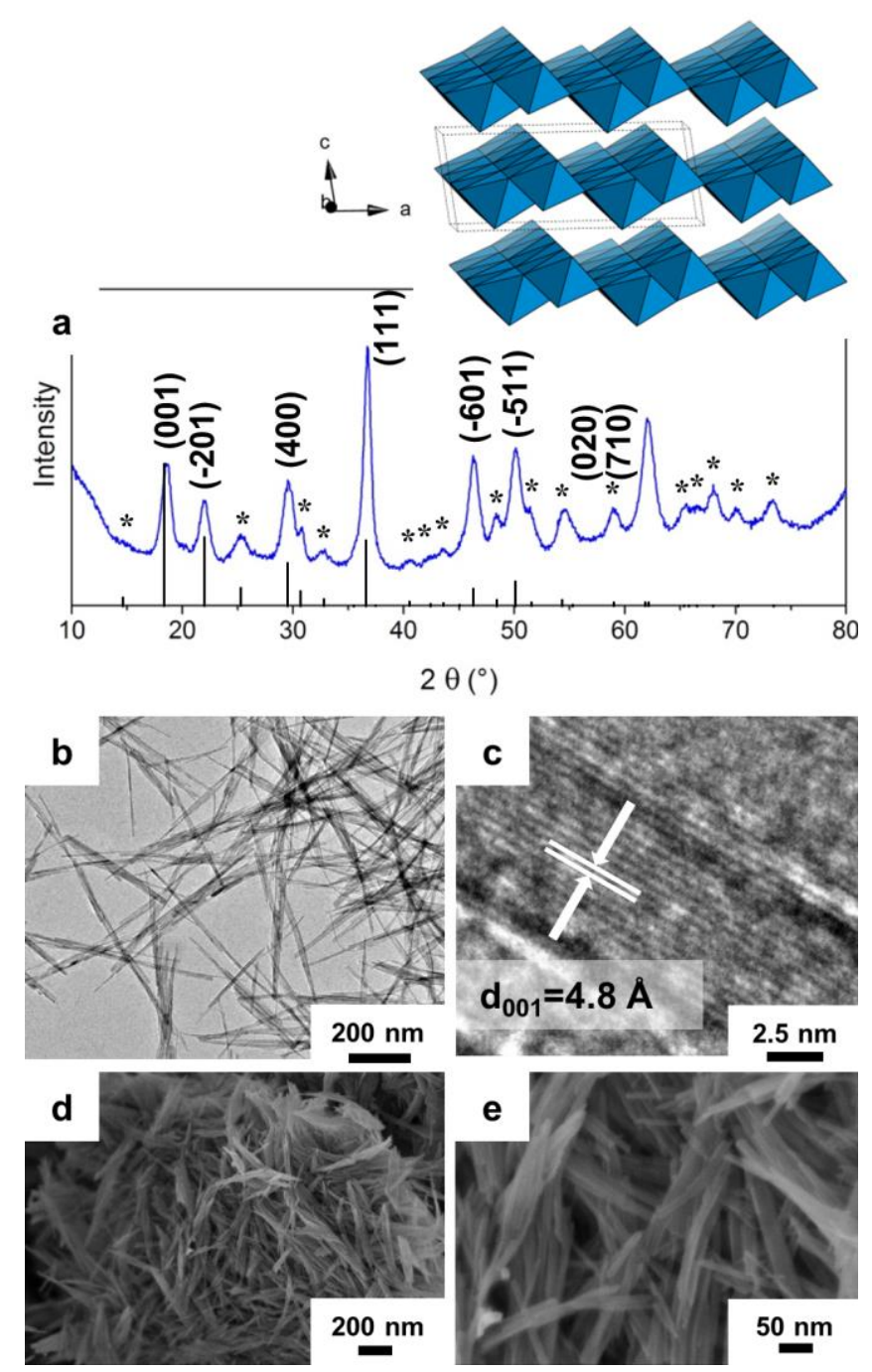

Figure 2. Structure (H atoms are omitted) and morphology of Häggite nanowires obtained at pH 3.6. (a) Powder XRD pattern indexed (*) according to the 04-011-6559 JCPDS card. (b) TEM, (c) HRTEM and (d-e) FESEM pictures of Häggite nanowires.

This work is dedicated to the development of a general and selective synthesis route towards both vanadium oxyhydroxides and a hydrate, namely Gain's hydrate (also called lenoblite $\left.\mathrm{V}_{2} \mathrm{O}_{4} \cdot 2 \mathrm{H}_{2} \mathrm{O}\right),{ }^{40}$ which is unreported as a nanostructured compound. We demonstrate that such a fine polymorphism control can be achieved through precipitation under soft aqueous conditions, by relying on $\mathrm{pH}$ as experimental lever. The three phases are obtained as nanocrystals and show the smallest dimensions ever reported. In the case of Häggite, we specifically addressed the reaction mechanism through X-ray Absorption Spectroscopy (XAS) 
experiments. Finally, the properties of Duttonite and Häggite versus $\mathrm{Li}^{+}$and $\mathrm{Na}^{+}$insertion in batteries are reported.

\section{RESULTS AND DISCUSSION}

\section{Synthesis and characterization of Häggite nanowires and Duttonite nanorods}

The synthesis relies on aqueous precipitation in the presence of hydrazine at $95{ }^{\circ} \mathrm{C}$ during 4.5 days. $\mathrm{pH}$ adjustment is the keystone to selectively obtain two different oxyhydroxides from very close experimental conditions. Indeed, the extreme $\mathrm{pH}$ dependence yields different phases at $\mathrm{pH} 4.0$ and 3.6-3.8, respectively. These compounds can be identified by XRD (Figures 1, 2 and S1 (Supporting Information)): at pH 4.0, Duttonite is obtained, while Häggite is the sole crystalline phase at $\mathrm{pH}$ 3.6-3.8. The broad peaks suggest nanocrystalline phases in both cases. Profile matching of the Häggite XRD pattern yields the following cell parameters: $\mathrm{a}=12.208 \AA, \mathrm{b}=2.997 \AA, \mathrm{c}=4.840 \AA, \beta=98.29^{\circ}$, in agreement with previous reports. $^{32,37}$

According to TEM and FESEM observations, Duttonite is obtained as short nanorods with a diameter of $5 \mathrm{~nm}$ and a length comprised between 5 and $25 \mathrm{~nm}$ (Figure 1). On the other side, Häggite (Figure 2) is synthesized as nanowires of large aspect ratio, with diameters $c a .10 \mathrm{~nm}$ and lengths from $200 \mathrm{~nm}$ to $1 \mu \mathrm{m}$. HRTEM (Figure 2c) highlights a $d$ spacing of $4.8 \AA$ characteristic of (001) octahedra sheet planes running along the growth axis of the wires, as previously reported. ${ }^{37}$ However, the herein reported nanowires are one order of magnitude smaller than the ribbons obtained by Wu et al. ${ }^{37}$ which were $200 \mathrm{~nm}$ large, 10 $40 \mathrm{~nm}$ thick and several microns long. Accordingly, we show herein an original morphology with the smallest dimensions reported. Due to their high aspect ratio, Häggite nanowires selfassemble into nanobundles (Figure 2d, e). 
Absorption spectra of both materials were calculated from reflectance measurements (Figure S2). Duttonite displays a higher absorption in the near-IR region than Häggite. The optical gap of Duttonite, reported here for the first time, is evaluated at $0.9 \mathrm{eV}$. The corresponding value for Häggite is $1.2 \mathrm{eV}$, in agreement with the data reported by $\mathrm{Wu}$ et al. ${ }^{37}$ FT-IR measurements (Figure S3) are consistent with both structures and data reported in the literature. ${ }^{41-43}$ No trace of ammonium groups, potentially produced by the degradation of hydrazine during the synthesis, is observed.

We addressed the stability of Häggite versus thermal treatment and exposure to air, which has not been discussed so far (Figure S4). Weight losses between $25-120{ }^{\circ} \mathrm{C}$ are attributed to physisorbed water whereas water formed during condensation of hydroxyl groups between the sheets is eliminated between 130 and $200{ }^{\circ} \mathrm{C}$. An oxidation reaction starts at $220{ }^{\circ} \mathrm{C}$ and leads to stoichiometric $\mathrm{V}_{2} \mathrm{O}_{5}$. Moreover, under air at room temperature, nanoscaled Häggite is amorphized within one month according to XRD measurements. The thermal stability under vacuum was also questioned. Heating at $200{ }^{\circ} \mathrm{C}$ under vacuum leads to the splitting of the nanowires into $10 \mathrm{~nm}$ spherical nanoparticles (not shown). Thus, nanoscaling increases Häggite's reactivity and decreases its stability compared to the bulk. ${ }^{37}$ Accordingly, the compound must be handled with care for properties investigations and implementation into future devices. Häggite samples were therefore stored in an argon-filled glove box and structure preservation was checked by XRD.

The specific surface area was evaluated from $\mathrm{N}_{2}$ sorption experiments using the Brunauer-Emmett-Teller (BET) model. Duttonite and Häggite samples show specific surface areas of 88 and $92 \mathrm{~m}^{2} \cdot \mathrm{g}^{-1}$, respectively. These values are the highest reported and confirm nanostructuration. 
Conditions leading to the selective crystallization of Häggite and Duttonite are close and only differ by $0.2-0.4 \mathrm{pH}$ units. This behavior can be attributed to the brutal change of $\mathrm{V}^{+\mathrm{IV}}$ solubility between $\mathrm{pH} 4.0$ and 3.6. Indeed, at $\mathrm{pH} 4.0$, no solubility is observed (the supernatant is colorless, and no $\mathrm{V}^{+\mathrm{IV}}$ aqueous complex is detected by UV visible measurements) whereas at $\mathrm{pH} 3.6$, the blue color of the supernatant is a clear evidence of the presence of $\mathrm{V}^{+\mathrm{IV}}$. The vanadium concentration in the supernatant at $\mathrm{pH} 3.6$ measured by UVvisible spectroscopy titration indicates that $10 \%$ of the total amount of vanadium introduced at the beginning of the synthesis is solubilized. The quantity of dissolved vanadium remains constant along the synthesis. In order to shed light on the synthesis mechanisms of Häggite, we monitored the course of the reaction by XRD, TEM and XAS. A particular attention was focused on the evolution of the local and long-range order structure, the vanadium oxidation state and the morphology of solid phases.

\section{Formation mechanism of Häggite}

First, XRD and TEM experiments were used to evaluate the time scale of phase transformations. Then, XAS experiments were performed to provide a deeper understanding on the structural evolution towards Häggite as well as to solve its formal oxidation state.

XRD and TEM experiments. The synthesis was stopped after 0-1-5 hours and 1-3-4.5 days of heating at $95{ }^{\circ} \mathrm{C}$. XRD patterns and TEM pictures of the intermediates are presented Figure 3. Up to $1 \mathrm{~h}$, an amorphous solid with ill-defined morphology appears (Figure 3a, b). After $5 \mathrm{~h}$ (Figure 3a, c), Gain's hydrate is obtained as a pure nanoscaled phase. The structure of this phase has never been elucidated but literature reports a composition identical to that of Duttonite $\left(\mathrm{VO}_{3} \mathrm{H}_{2}\right) .{ }^{44}$ Gain's hydrate is obtained as $40 \mathrm{~nm}$ large, $300 \mathrm{~nm}-1 \mu \mathrm{m}$ long and only a few nanometers thick twisted ribbons, with a length distribution that corresponds to the length 
polydispersity of final Häggite nanowires. Evolution from Gain's hydrate to Häggite is evidenced by the inversion of the relative intensities of the $14^{\circ}$ and $18^{\circ}(2 \theta, \mathrm{Cu} \mathrm{K \alpha}) \mathrm{XRD}$ peaks starting after 1 day of reaction (Figure 3a). At the same time, the biggest ribbons have disappeared and only $300 \mathrm{~nm}$-long ribbons are present, which are less twisted than those observed at $5 \mathrm{~h}$ (Figure 3d). After 3 days (Figure 3f), Häggite rods are detected (10 nm of diameter and 50-100 nm of length). Few ribbons of Gain's hydrate (40 nm large and $300 \mathrm{~nm}$ long) are still present (pink arrows in Figure 3f), in agreement with XRD (Figure 3a). After 4.5 days (Figure 3a, g), Gain's hydrate completely disappears and pure Häggite nanowires are obtained, with increasing length while the diameter does not change significantly $(10 \mathrm{~nm})$. This preliminary study shows that Häggite formation starts with the precipitation of an amorphous solid, followed by crystallization of Gain's hydrate. As specified above, the structure of this phase is not reported in the literature. Nevertheless, FTIR provides some hints about its local structure, which clearly differs from those of Duttonite and Häggite. In agreement with previous reports, ${ }^{45}$ the 3500 and $3250 \mathrm{~cm}^{-1}$ bands (Figure S3) highlight structural water molecules in well-defined crystallographic sites. In addition, the stretching vibration of $\mathrm{V}=\mathrm{O}$ is observed at $950 \mathrm{~cm}^{-1}$, while the band at $780 \mathrm{~cm}^{-1}$ is characteristic of the vibrations of V-O-H groups.

The effect of stirring during heating at $95^{\circ} \mathrm{C}$ has also been scrutinized (Figure S5). XRD shows that the formation and the transformation of Gain's hydrate is faster under stirring and starts as soon as the reaction begins. The morphology of the final particles is also impacted: nanowires keep a diameter of $10 \mathrm{~nm}$ but are shortened, from $200 \mathrm{~nm}-1 \mu \mathrm{m}$ without stirring to $100-200 \mathrm{~nm}$ with stirring, resulting in a narrower size distribution characterized by an aspect ratio of 10 to 20 . The short wires aggregate on their lateral faces. 
a
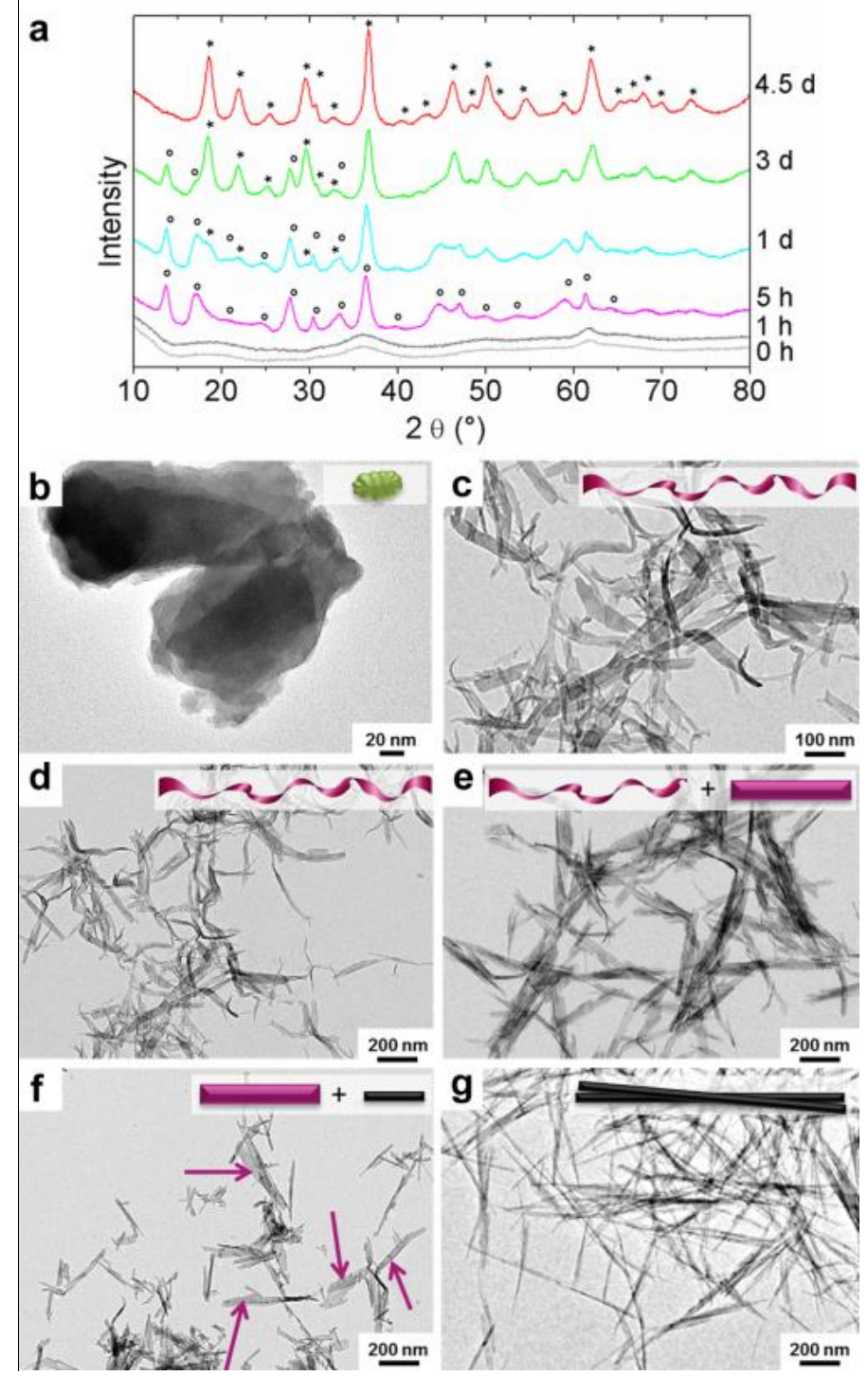

Figure 3. Kinetic study of Häggite formation: XRD patterns (a) and TEM pictures (b-g) of various samples isolated after $0 \mathrm{~h}(\mathrm{~b}), 1 \mathrm{~h} \mathrm{(c),} 5 \mathrm{~h}(\mathrm{~d}), 1$ day (e), 3 days (f) and 4.5 days (g) of heat treatment at $95{ }^{\circ} \mathrm{C}$, with an initial $\mathrm{pH}$ of 3.6. Insets show schematic representations of the corresponding morphology. XRD peaks corresponding to Häggite (4.5 days) and Gain's hydrate $(5 \mathrm{~h})$ are indicated by stars and circles, respectively. When binary mixtures of Häggite and Gain's hydrate are present, only the peaks between 10 and $35^{\circ}$ are indicated for the sake of clarity.

XAS study: composition and local structure of Duttonite and Häggite. To reach a deeper insight into the reaction mechanism, we addressed by XAS the evolution of the metal coordination sphere, the local structure, and the vanadium oxidation state in the course of the 
reaction. Since the pioneering work of Wong et al. ${ }^{46}$ recently completed by Chaurand et al., ${ }^{47}$ the XANES part of V K-edge XAS spectra is recognized as a powerful tool to derive information on vanadium oxidation state and the geometry of its first coordination sphere. In particular, linear correlation between the oxidation state of known compounds and the position of the rising edge, $\mathrm{E}_{1 / 2}$ corresponding to $50 \%$ level of the normalized absorbance, is often used to evaluate the oxidation state of unknown vanadium phases. ${ }^{47,48}$ When the mean oxidation degree increases, the position of the $E_{1 / 2}$ parameter is linearly shifted to higher energies. Furthermore, the presence of pre-edge features resulting from transitions of $1 \mathrm{~s}$ vanadium core electrons towards molecular orbitals in which $3 \mathrm{~d}$ states are hybridized with vanadium $\mathrm{p}$ levels is also very informative about the stereochemical arrangement around vanadium: formally forbidden for pure octahedral symmetry, the intensity of the pre-edge feature increases for distorted arrangement and non-centrosymmetrical arrangement like tetrahedral symmetry, everything else being equal in particular the oxidation state of vanadium. The aforementioned trends are clearly verified with the XANES analysis of several vanadium oxy-compounds (Table S1) with various vanadium oxidation states and coordination polyhedra $^{46}$ (Figure 4). For pentavalent vanadium references, the highest prepeak (Figure 4a, b) is observed for the aqueous solution of $\mathrm{NaVO}_{3}$ in which vanadium is embedded in a pure tetrahedral symmetry whereas for tetravalent references, the intensity of the pre-edge peak of $\mathrm{V}_{2} \mathrm{O}_{4}$ is lower than the one of $\mathrm{VOSO}_{4} \cdot 3 \mathrm{H}_{2} \mathrm{O}$ as a result of a more symmetrical octahedral symmetry. Figure 4d reports the correlation between the energy value measured for the normalized absorption $\mu(E)=0.5$ (Figure 4c) and the oxidation degree of reference samples. The correlation is coherent with reported data. ${ }^{46}$ The $\mathrm{E}_{1 / 2}$ positions of Duttonite $\left(\mathrm{VO}(\mathrm{OH})_{2}\right)$ and Häggite are $5479.3 \mathrm{eV}$ and $5478.7 \mathrm{eV}$ (Figure 4c), respectively. These values unambiguously evidence that Duttonite as well as Häggite possess solely $\mathrm{V}^{+\mathrm{IV}}$ 
cations (Figure 4d). This result confirms Häggite's formula $\mathrm{V}_{2} \mathrm{O}_{3}(\mathrm{OH})_{2}$ corrected by $\mathrm{Wu}$ et $a l .{ }^{37}$ from the original one $\left(\mathrm{V}_{2} \mathrm{O}_{2}(\mathrm{OH})_{3}{ }^{32}\right)$.

The EXAFS spectra and corresponding Pseudo Radial Distribution Function (PRDF) of Duttonite and Häggite are presented Figure S6 in comparison with some of the vanadium oxy-compounds discussed in Table S1. Both phases display medium range order with strong contributions at distances $\mathrm{R}>2 \AA$ but with clear differences in shape. The EXAFS spectrum of Duttonite can be satisfactorily fitted to a strongly distorted octahedral $\mathrm{V}^{+\mathrm{IV}}$ environment (Figure S7), with one oxygen at $1.64 \AA$, four oxygens at $1.99 \AA$ and 1 oxygen at $2.38 \AA$. The structural parameters obtained from this fit are gathered in Table S2. The shortest V-V distance is at $3.09 \AA$. All in all, the EXAFS data are in agreement with the reported Duttonite structure. ${ }^{32-36}$

Comparison of the pre-edge peak intensity for Duttonite and Häggite suggests that in the latter structure, vanadium is embedded in a more symmetrical environment. Indeed, the intensity of the pre-edge feature for Häggite is even lower than the one found for $\mathrm{V}_{2} \mathrm{O}_{4}$. Considering the crystallographic structure reported for Häggite by Evans et al. ${ }^{32}$ and more recently by $\mathrm{Wu}$ et al., ${ }^{37}$ a satisfactory least-square fitting of the EXAFS data (Figure S7, Table S2) of the Häggite obtained after 6.5 days of ageing at $95{ }^{\circ} \mathrm{C}$ confirms the octahedral coordination with 5 oxygen atoms at $2.01 \AA$ and 1 oxygen atom at $1.69 \AA$. The latter distance corresponds to the oxygen atom connecting two double chains of equivalent octahedra sharing edges. These chains extend along the $\boldsymbol{b}$ axis. The $1.69 \AA$ distance is shorter than the one from the reported crystallographic structure, equal to $1.82 \AA{ }^{32,37}$ In addition, the nearest vanadium neighbours are found at 3.07, 3.17 and $3.37 \AA$, versus $3.00,3.15$ and $3.63 \AA$ in the reported structure. The first two values correspond to distances within the linear chains of octahedra sharing edges. The third value reflects the connection of two double chains by octahedra sharing corners. In agreement with the shortening of the associated V-O bond, the inter-chain 
$\mathrm{V}-\mathrm{V}$ distance between vanadium atoms sharing this oxygen is found at shorter distance (3.37 $\AA$ ) than the one reported at $3.63 \AA .{ }^{32}$ All in all, EXAFS data are in good agreement with the structure of the Häggite double chains of octahedra and XAS measurements confirm the $\mathrm{V}^{\mathrm{IV}}{ }_{2} \mathrm{O}_{3}(\mathrm{OH})_{2}$ formula and the related structure proposed recently, ${ }^{37}$ in opposition to previous works. $^{32,39}$ The distance between the double chains determined by EXAFS is shorter than the values from the reported crystallographic data. ${ }^{32,37}$

a
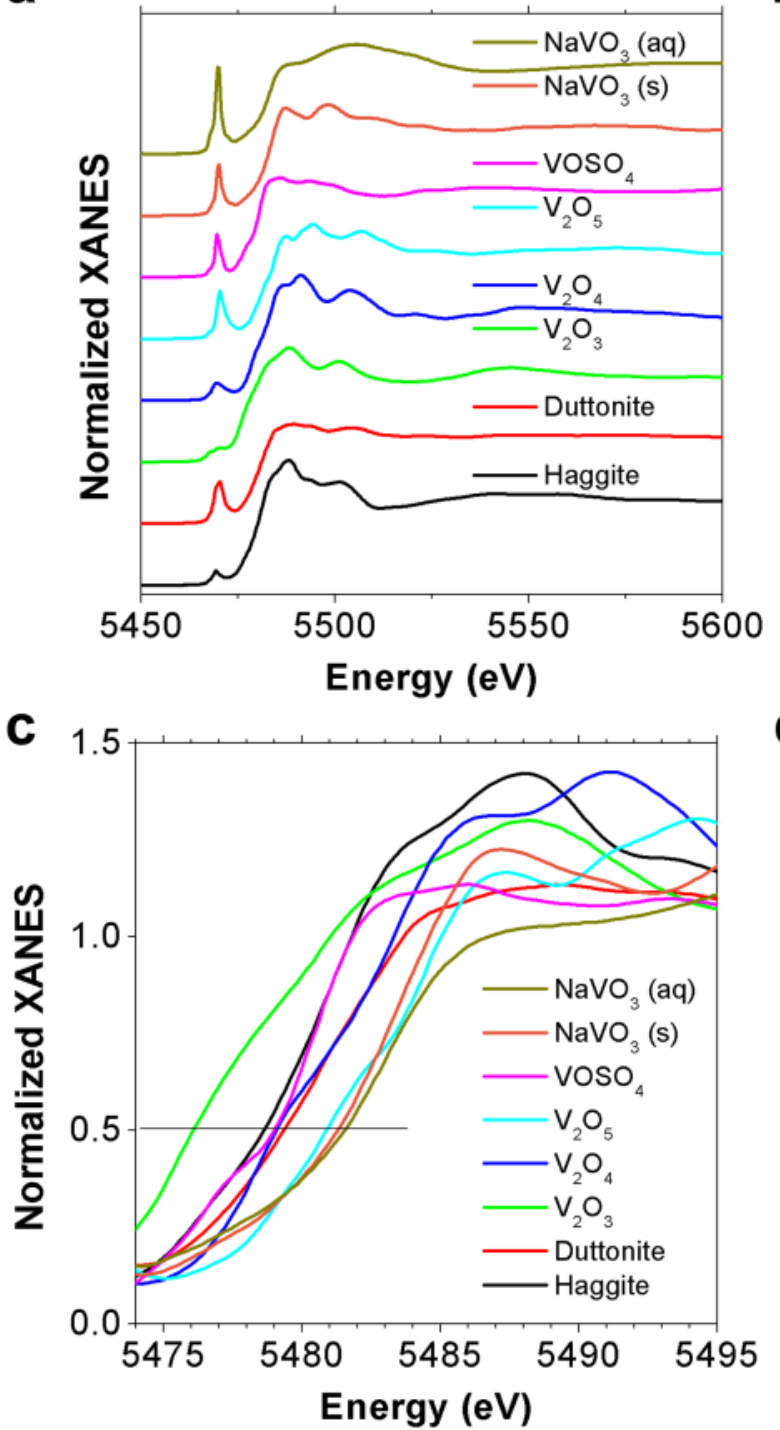

b

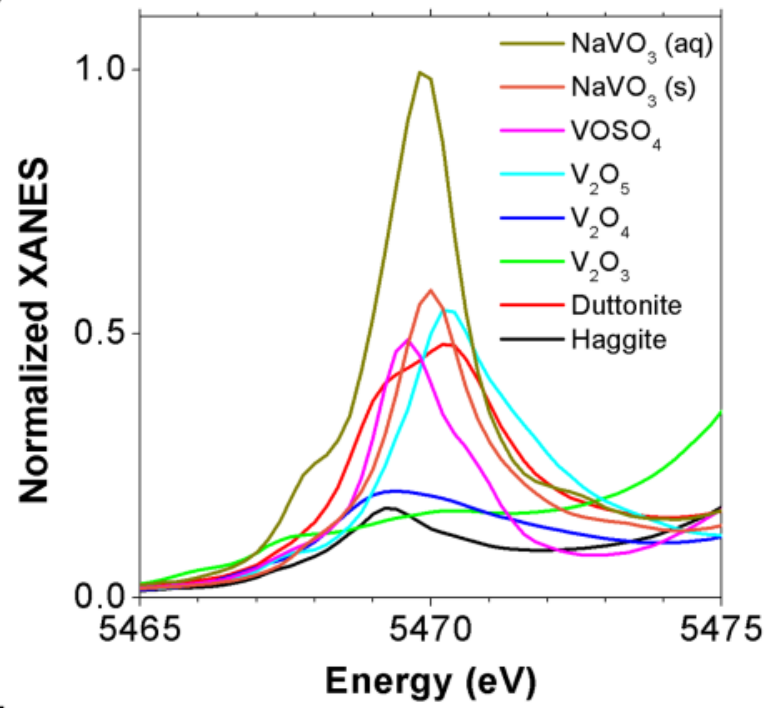

d

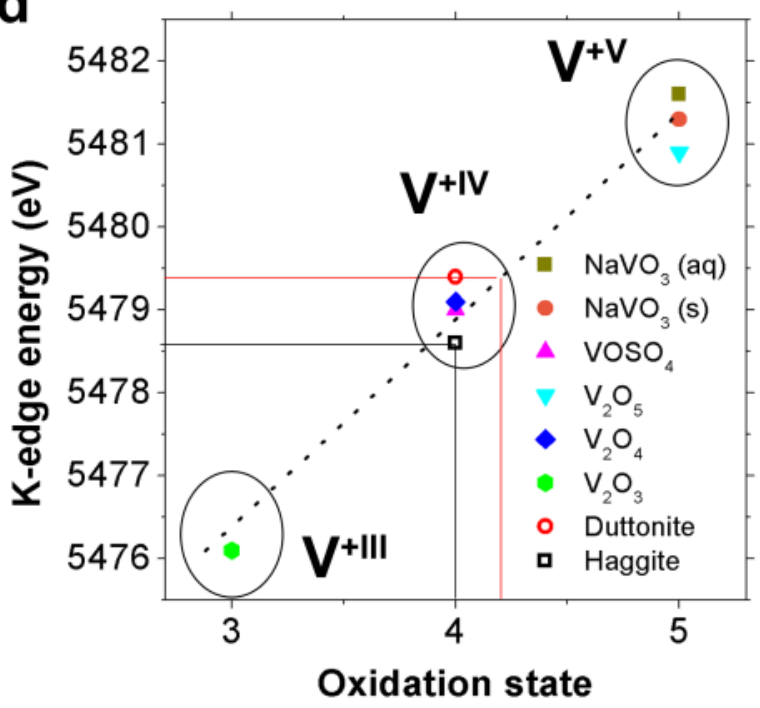

Figure 4. XAS analysis of Häggite, Duttonite and references (Table S1), Häggite in black, Duttonite in red. (a) Normalized XAS spectra. (b) Enlargement of the pre-peak region. (c) Enlargement of the edge region. (d) Position of the reference edge energies as a function of the oxidation state. Häggite (black) and Duttonite (red) are clearly lying in the $\mathrm{V}^{+\mathrm{IV}}$ area. 
XAS study: first steps of the reaction and amorphous first intermediate. The course of the reaction was first monitored by XAS (Figure 5) by taking aliquots during the first stage where an X-ray amorphous phase is formed (Figure 3a from 0 to $1 \mathrm{~h}$ and Figure 5). The reaction medium is analyzed at 4 different stages: (1) the starting solution $\left(\mathrm{NaV}^{\mathrm{V}} \mathrm{O}_{3}, \mathrm{pH}\right.$ 7.2), (2) the dark brown solution obtained immediately after addition of hydrazine (10 eq.), (3) the suspension resulting from $\mathrm{pH}$ adjustment by $\mathrm{HCl}$ addition $(\mathrm{pH} 3.6)$ and (4) the suspension obtained after $1 \mathrm{~h}$ of thermal treatment. The edge energy (Figure $\mathbf{5 b}$ and $\mathbf{e}$ ) provides quantitative information about the evolution of the vanadium oxidation state. Surprisingly, reduction happens in two steps: half of the $\mathrm{V}^{+\mathrm{V}}$ ions are first reduced to $\mathrm{V}^{+\mathrm{IV}}$ as soon as hydrazine is added, then the remaining $\mathrm{V}^{+\mathrm{V}}$ are reduced upon acid addition, along with precipitation. The vanadium $\mathrm{K}$ edges of the samples obtained after $\mathrm{pH}$ adjustment and after 1 hour at $95{ }^{\circ} \mathrm{C}$ are identical and show that the final oxidation state is reached at ambient temperature: only $\mathrm{V}^{+\mathrm{IV}}$ is present in the suspension when the thermal treatment starts. No evidence of a transitory $\mathrm{V}^{+\mathrm{III}}$ compound is detected as initially proposed by Wu et al ${ }^{37}$

According to the literature, the initial $\mathrm{NaVO}_{3}$ solution is composed of vanadate polyanions with moderate molecular weight based on $\mathrm{V}^{+\mathrm{V}}$ in tetrahedral coordination. ${ }^{49}$ The corresponding distance to first neighbors of $1.74 \AA$ (V-O bonds) is located at $1.4 \AA$ on the PRDF (Figure 5f). When hydrazine is added, this distance is split into two contributions, while a contribution of second neighbors appears between 2.5 and $3.5 \AA$ on the PRDF. Splitting of the first peak is consistent with the formation of a $\mathrm{V}^{+\mathrm{IV}}$ complex bearing in the first coordination shell a short $\mathrm{V}=\mathrm{O}$ bond at $1.62 \AA$ and longer $\mathrm{V}-\mathrm{N}$ bonds at $2.10 \AA$, as reported in a square-based pyramidal $\mathrm{V}^{+\mathrm{IV}}$ complex. ${ }^{50}$ The appearance of the distance to second neighbors suggests the formation of oligomers containing several V ions, which may be connected by hydrazine acting as bidentate ligand or by its nitrogen-containing degradation 
products. Moreover, the intensity of the pre-peak (Figure 5a and $\mathbf{b}$ ) is significantly lowered at this step, showing that the symmetry of the vanadium environment is increased. When the $\mathrm{pH}$ is adjusted at 3.6, the first contribution in the PRDF is not split anymore and is slightly shifted at longer distances on the PRDF (1. $5 \AA$ ) compared to the initial $\mathrm{NaVO}_{3}$ solution. Besides, the increasing contribution of second neighbors through a broad peak at high distances $(2.8 \AA$ on the PRDF) indicates further inorganic polymerization and marks precipitation. Note that the pre-edge and edge features for the suspension after $1 \mathrm{~h}$ of heating are close to those of an aqueous solution of $\mathrm{VOSO}_{4} \cdot 3 \mathrm{H}_{2} \mathrm{O}$ (Figure 5c and $\mathbf{d}$ ), corresponding to $\mathrm{V}^{+\mathrm{IV}}$ in a strongly distorted octahedral environment. 
a

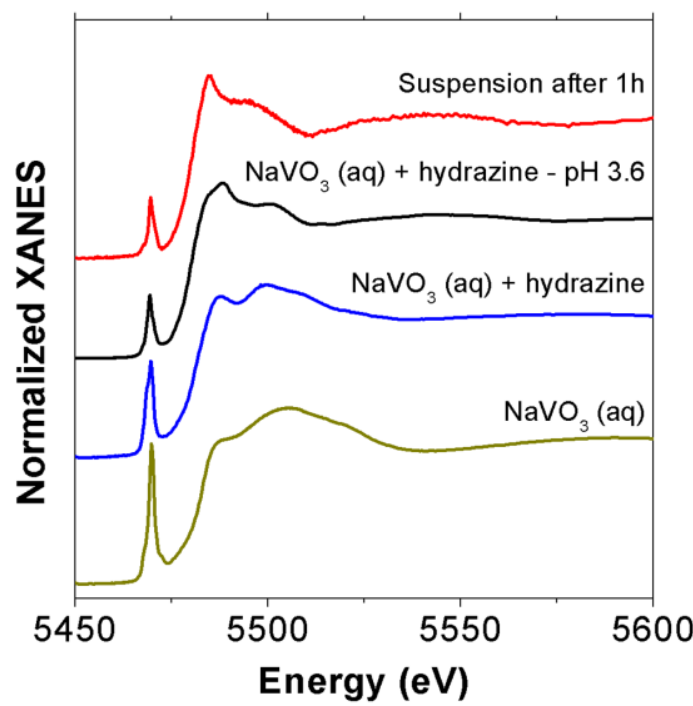

C
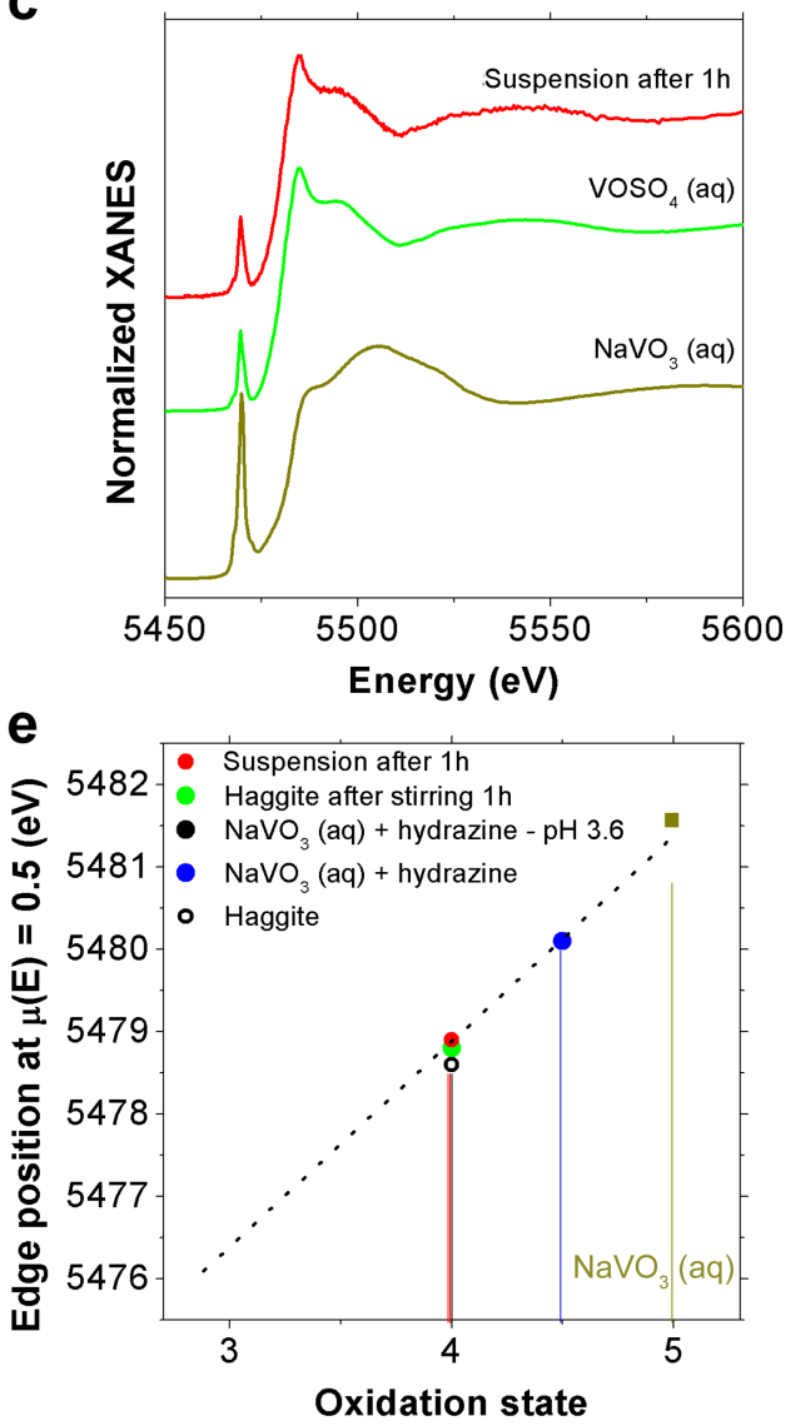

b
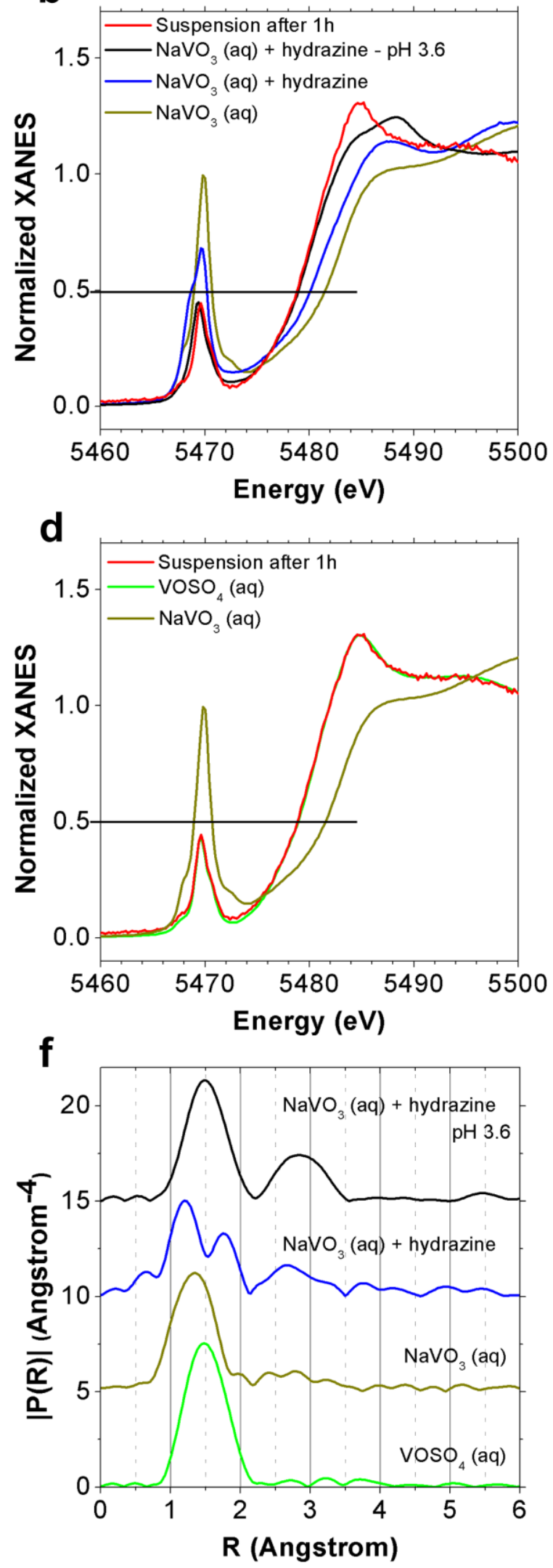

Figure 5. XAS study of the first hour of Häggite formation. (a) XAS spectra of the starting $\mathrm{NaVO}_{3}$ solution, the $\mathrm{NaVO}_{3}$ solution after addition of hydrazine, the suspension obtained 
after $\mathrm{pH}$ adjustment at 3.6 and the suspension after one hour at $95^{\circ} \mathrm{C}$. (b) Enlargement of the edge and pre-edge area. (c) XAS spectra of the starting $\mathrm{NaVO}_{3}$ solution, the suspension after one hour at $95{ }^{\circ} \mathrm{C}$ and reference of $\mathrm{VOSO}_{4}$ in aqueous solution. (d) Enlargement of the edge and pre-edge area. (e) Energy position of the edge for the different samples presented in a-d and positioned on the references correlation line from Figure 4d. (f) Pseudo Radial Distribution Function obtained by Fourier transform of the EXAFS part of the spectra.

XAS study: crystallization and transformation of Gain's hydrate into Häggite. The kinetic study from $1 \mathrm{~h}$ to 5 days (Figure 6) was performed on pastes obtained from aliquots of the reaction medium after removal of the supernatant by centrifugation. In the XAS fluorescence mode, the contribution of the solubilized species $(10 \mathrm{~mol} \%$ of vanadium according to UVvisible spectroscopy) is negligible and the signal originates from the solid phase. The reaction was run under stirring to speed up the process. We checked that the phase evolution was similar, that Gain's hydrate was obtained at $5 \mathrm{~h}$ with or without stirring. Afterwards, structural evolution after $5 \mathrm{~h}$ is faster under stirring (Figure S8).

The vanadium K-edge energy is not modified upon heating and confirms that the oxidation state remains +IV during the reaction (Figure 6b). Upon aging, the intensity of the $1 \mathrm{~s} \rightarrow 4 \mathrm{p}$ band $(5485 \mathrm{eV})$ increases while the $1 \mathrm{~s} \rightarrow 3 \mathrm{~d}$ band (pre-edge band at $c a .5470 \mathrm{eV}$ ) decreases. The pre-peak intensity continuously drops during temperature treatment, showing again that the geometry around vanadium is becoming more centrosymmetric: from tetrahedral coordination in the initial solution, the symmetry evolves towards a less distorted octahedron. These data provide unprecedented insight into the local structure of Gain's hydrate $\left(5 \mathrm{~h}\right.$ at $\left.95{ }^{\circ} \mathrm{C}\right)$, which structure is currently unknown. According to the relatively high pre-peak intensity, vanadium is in a non-centrosymmetric environment. The presence of a set of isobestic points at 5507, 5533 and $5577 \mathrm{eV}$ (Figure S9) undoubtedly indicates that 
evolution is taking place between two defined compounds, namely Gain's hydrate and Häggite according to XRD measurements.

Until $5 \mathrm{~h}$, the PRDF shows only one peak at $2.8 \AA$ for the second nearest neighbors, while a third contribution increases at $5.6 \AA$. At $5 \mathrm{~h}$, Gain's hydrate is obtained as a pure phase according to XRD. Hence, 2.8 and 5.6 $\AA$ PRDF peaks are characteristic of Gain's hydrate. From 5 to 24 h, the hydrate evolves into Häggite according to XRD. This latter phase transformation is accompanied by a splitting of the second correlation peak into two distances, while the peak at $5.6 \AA$ decreases.

a

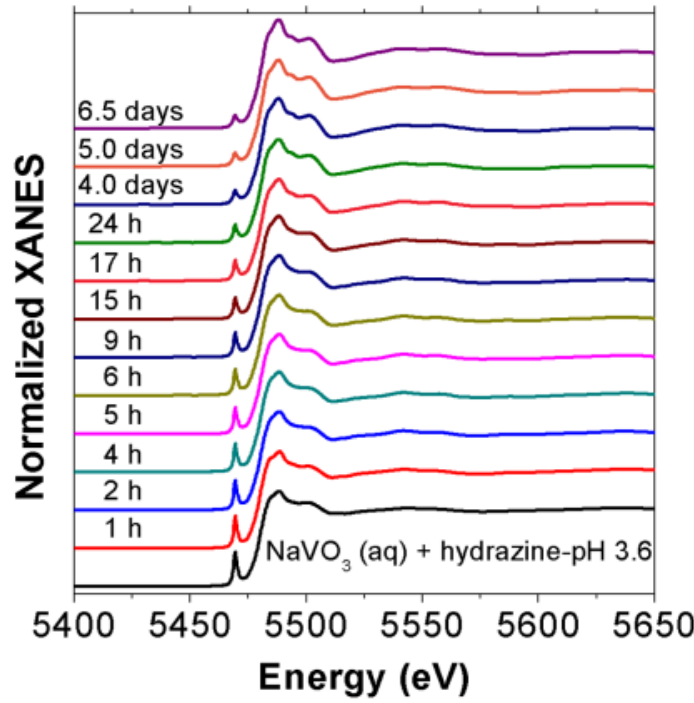

b

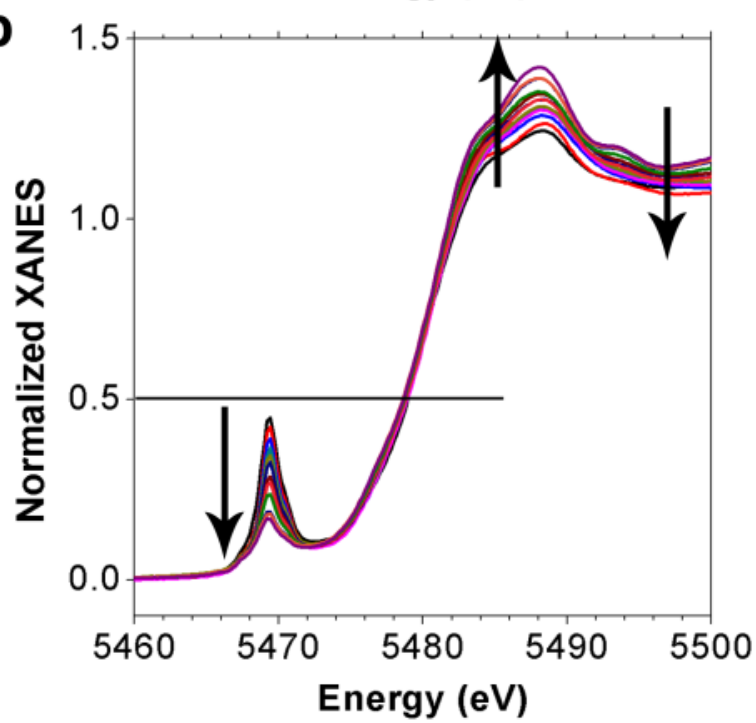

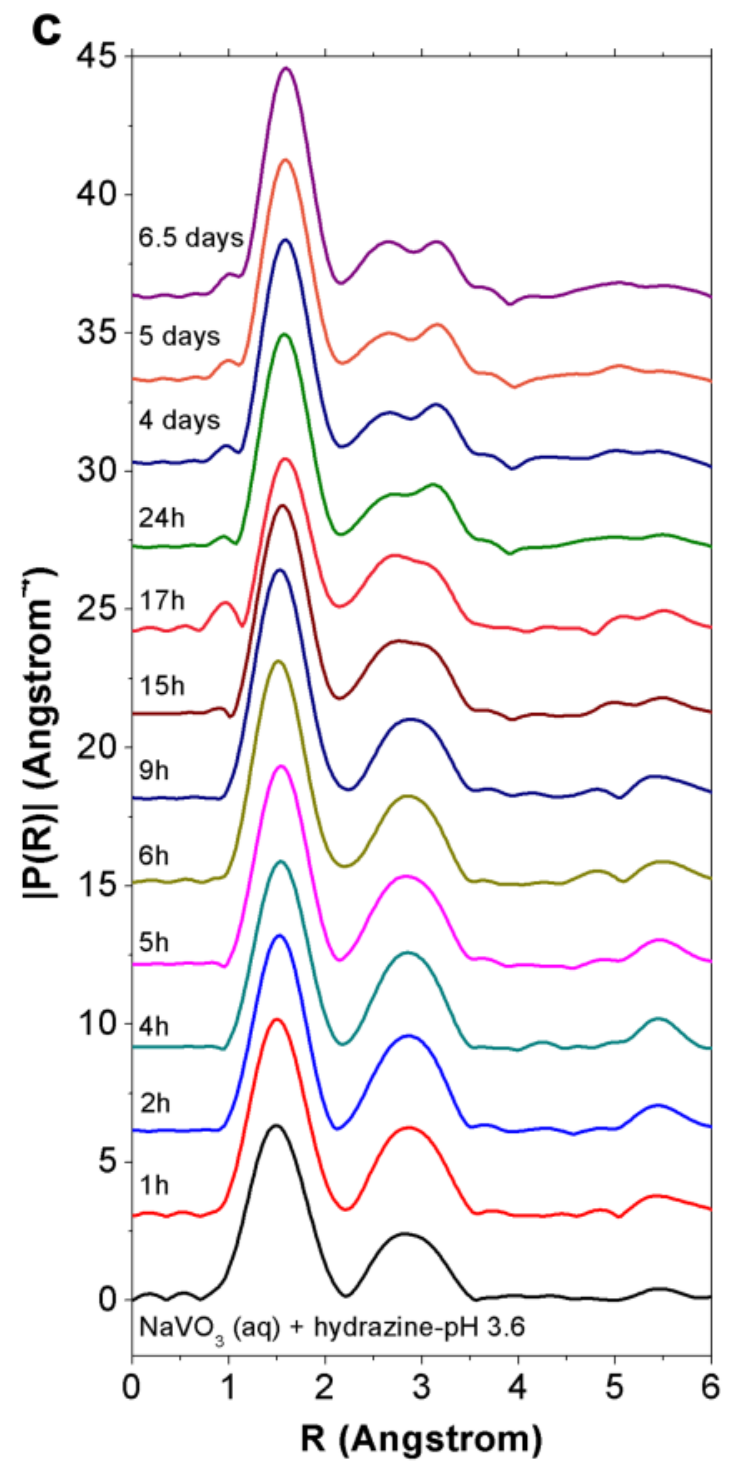

Figure 6. XAS kinetic study of Häggite crystallization at $95{ }^{\circ} \mathrm{C}$ under stirring. The solid 
samples are isolated from the reaction medium at each reaction time, from $1 \mathrm{~h}$ to 6.5 days. (a) XAS spectra. (b) Enlargement of the edge/pre-edge area. Arrows indicate the general evolution during the reaction. (c) Corresponding Pseudo Radial Distribution Functions.

XAS study: local structure of Gain's hydrate. To propose a structural model for Gain's hydrate, one can point out that the XANES pre-edge intensities of Gain's hydrate and of Duttonite are of the same order of magnitude (Figure S10). Besides, Gain's hydrate (the lenoblite mineral) is always associated with Duttonite in ores. ${ }^{40}$ Both points suggest that the structures of Gain's hydrate and of Duttonite are related. Therefore, a structural model inspired by the distorted octahedra arrangement in Duttonite has been used for fitting the filtered EXAFS signal of Gain's hydrate, resulting in a short V-O distance at $1.64 \AA$, a large one at $2.29 \AA$ and four V-O distances at $2.00 \AA$ (Figure S7, Table S2). The first nearest and second nearest V-V distances are found at $3.08 \AA$ and $3.40 \AA$. Note that both values are also observed in Häggite, where $3.08 \AA$ corresponds to octahedra sharing edges in the double chains along the $\boldsymbol{b}$ axis of the Häggite structure. $3.40 \AA$ fits the inter-chain connection through the $\mathrm{O}$ atom at $1.64 \AA$. Finally, a third V-V distance at $5.97 \AA$ satisfactorily reproduces the main feature of the peak at $\sim 5.6 \AA$ on the PRDF. This distance results from the contribution of third nearest $\mathrm{V}$ atoms aligned along the same chain in Häggite. Noteworthy, the only V-V distance of Häggite missing in Gain's hydrate is at $3.21 \AA$ and is characteristic of the double chains of octahedra. Hence, contrary to Häggite, Gain's hydrate can be described on the basis of single chains of octahedra and not double chains. Therefore, a structural subunit consisting in two single edge-sharing octahedra chains, linked by corners, is proposed as the building block of Gain's hydrate (Figure 7 top). To comply with the reported formula of Gain's hydrate $\mathrm{V}_{2} \mathrm{O}_{4} \cdot 2 \mathrm{H}_{2} \mathrm{O}$, the building block must be terminated by water molecules. Besides the $\mathrm{V}$ neighbors within the building-block, no other $\mathrm{V}-\mathrm{V}$ distance is detected, thus indicating 
structural disorder between the dimers (corner sharing chains). Consequently and in agreement with the chemical formula, we suggest that overall half of the vanadium atoms are 6-coordinated with a water molecule in the coordination sphere, while the other half is 5 coordinated in a square pyramidal environment. These $\mathrm{H}_{2} \mathrm{O}$ molecules are likely labile and able to hop from one vanadium (IV) to another one within a chain and between dimer building units, so that EXAFS data report overall one single, strongly distorted, octahedral environment. In agreement with this assumption, fitting EXAFS data with 5.5 oxygen neighbors for vanadium yields similar reliability than with $6 \mathrm{O}$ neighbors, thus pleading in favor of 5-fold coordination for half of the $\mathrm{V}^{4+}$ cations.
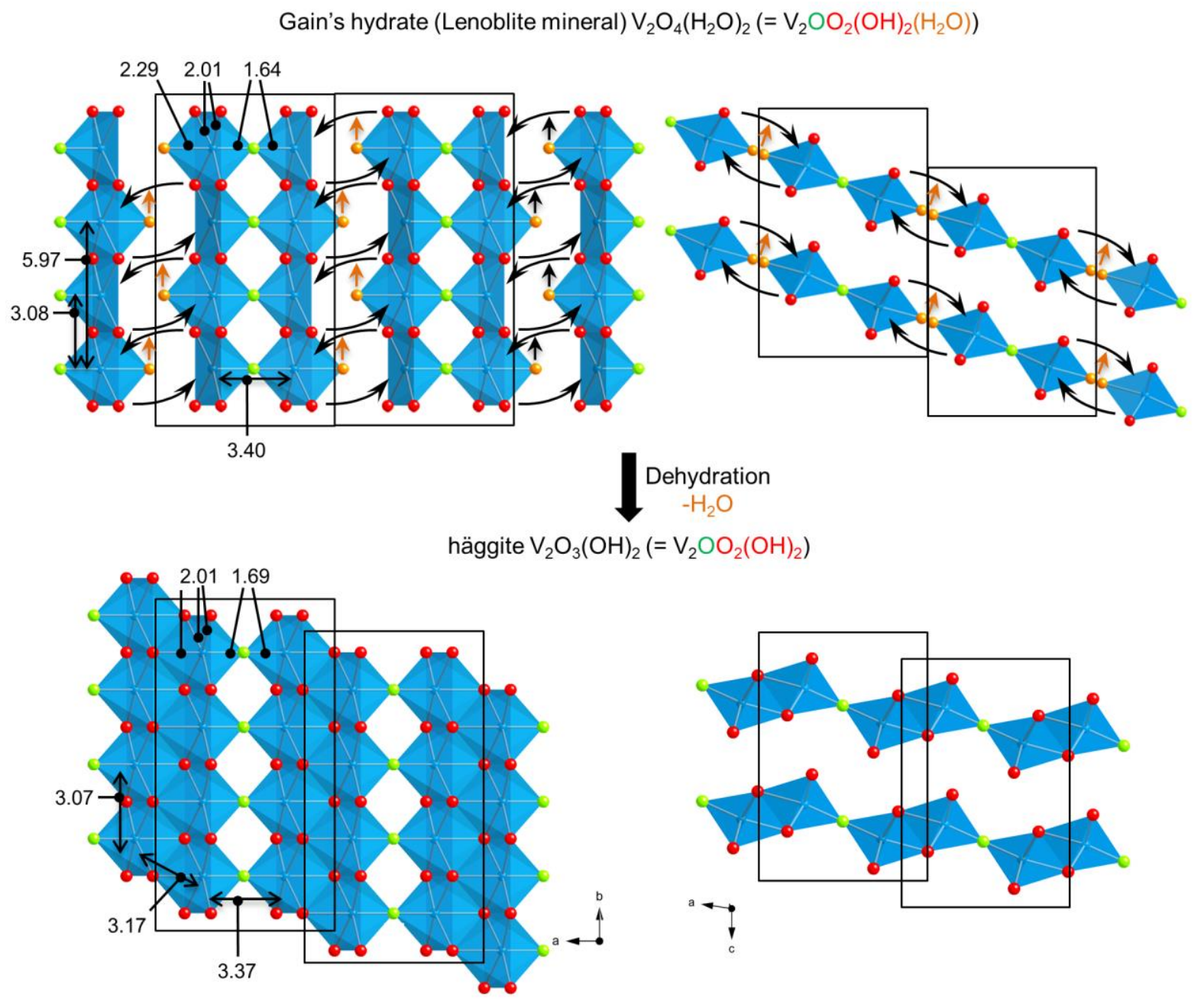

Figure 7. Proposition of structural arrangement in Gain's hydrate based on structural subunits consisting in dimers of single chains of edge sharing octahedra. Topotactic evolution towards 
Häggite by dehydration (orange arrows) and condensation between the dimers of single chains. Values obtained from EXAFS data are given in Angström. Note that the relative arrangement of the two layers of chains (top right) is only suggested based on the corresponding order in Häggite (bottom right). Besides, water molecules in Gain's hydrate are labile and can hop from a vanadium site to another one.

Mechanism of the transformation of Gain's hydrate into Häggite. The chemical model for Gain's hydrate provides a straightforward topotactic mechanistic pathway towards Häggite. Indeed, evolution from Gain's hydrate $\mathrm{V}_{2} \mathrm{O}_{4} \cdot 2 \mathrm{H}_{2} \mathrm{O}$ (or $\mathrm{V}_{2} \mathrm{O}_{3}(\mathrm{OH})_{2} \cdot \mathrm{H}_{2} \mathrm{O}$ ) to Häggite $\mathrm{V}_{2} \mathrm{O}_{3}(\mathrm{OH})_{2}$ occurs simply through dehydration. The proposed model of Gain's hydrate (Figure 7 top) suggests that condensation of the building blocks made of two single chains would lead to dehydration and the formation of the double chains of octahedra, characteristic of the Häggite structure. Noteworthy, according to this model, the formation of Häggite by condensation of the building blocks would proceed through the appearance of shear planes. Such a structural evolution is well known in Magnéli phases, especially in $\mathrm{V}_{\mathrm{n}} \mathrm{O}_{2 \mathrm{n}-1}$ with mixed valence $\mathrm{V}^{\mathrm{IV}} / \mathrm{V}^{\mathrm{III}}$, from the rutile $\mathrm{VO}_{2}$ structure. ${ }^{51-53}$ This proposed mechanism is also in line with the similar length distribution of the initial Gain's hydrate nanoribbons and the final Häggite nanowires.

Overall formation mechanism. According to XRD, TEM and XAS studies, one can describe the reaction mechanism towards Häggite through the following steps:

First, hydrazine is added at room temperature to a solution of metavanadate ions where $\mathrm{V}^{\mathrm{V}}$ is in a tetrahedral environment. Hydrazine coordinates $\mathrm{V}^{\mathrm{V}}$, leading to soluble inorganic vanadium oxo-oligomer, in which half of the vanadium ions are reduced to $\mathrm{V}^{\mathrm{IV}}$.

Second, $\mathrm{pH}$ is adjusted to 3.6, leading to the precipitation of an amorphous solid in which vanadium is in a distorted octahedral coordination, concomitantly with the reduction of the 
remaining $\mathrm{V}^{\mathrm{V}}$ to $\mathrm{V}^{\mathrm{IV}}$. The oxidation state does not evolve anymore during the next heating step. Noteworthy, although precipitation started, at this stage part of the vanadium species are still solubilized in the reaction medium (ca. $10 \%$ of vanadium ions, based on UV-visible spectroscopy). On the contrary, in the case of Duttonite, no soluble species were detected.

Third, from $1 \mathrm{~h}$ to $5 \mathrm{~h}$, Gain's hydrate $\mathrm{V}_{2} \mathrm{O}_{4} \cdot 2 \mathrm{H}_{2} \mathrm{O}$ crystallizes, based on the assembly of building blocks made of two single chains of edge-sharing square-based pyramids or distorted octahedra. Part of the vanadium in these building blocks is coordinated by a labile water molecule that can jump from one site to the other, thus yielding overall a strongly distorted octahedral environment for vanadium ions.

After $5 \mathrm{~h}$, evolution occurs from Gain's hydrate to Häggite by a topotactic dehydration that consists in the condensation of the building blocks made of two single chains through the formation of shear planes.

Noteworthy, the model for Gain's hydrate proposed herein provides an explanation for the absence of Duttonite $\mathrm{VO}(\mathrm{OH})_{2}$ from Gain's hydrate. Indeed, in Häggite and Gain's hydrate, the shortest V-O bonds are face-to-face (Figure 7), thus yielding two corner-sharing singlechains as common building blocks. On the contrary, in Duttonite, the shortest V-O bonds alternate with longest V-O bonds along the $\mathrm{b}$ axis (Figure 1). Duttonite cannot be described as the assembly of the building blocks present in Gain's hydrate, so that structural evolution from $\mathrm{V}_{2} \mathrm{O}_{4} \cdot 2 \mathrm{H}_{2} \mathrm{O}$ to $\mathrm{VO}(\mathrm{OH})_{2}$ is not likely to occur. Hence, our study strongly suggests that Gain's hydrate is not an intermediate towards Duttonite. This conclusion suggests that Gain's hydrate is formed at $\mathrm{pH} 3.6$ from an amorphous precursor (on the course to Häggite) but not at $\mathrm{pH} 4.0$ (leading ultimately to Duttonite). This change in the reaction pathway relates to the varying solubility of vanadium species: Gain's hydrate might only crystallize when vanadium is sufficiently soluble ( $10 \mathrm{~mol} . \%$ in solution), thus pointing out the need for large structural 
reorganization from the amorphous precursor. This structural evolution is enabled at $\mathrm{pH} 3.6$ where dissolution-recrystallization mechanism could take place. On the opposite, at $\mathrm{pH} 4.0$ the initial amorphous solid is likely to evolve to Duttonite by in situ crystallization.

Electrochemical properties. Because soft chemistry allows selective formation of both oxyhydroxides, we underwent the first study of the electrochemical behavior of Duttonite and Häggite. The ability of vanadium compounds to store lithium and sodium ions, together with the respective lamellar and wire structures seem indeed promising for increasing the capacity and its stability at high charge/discharge rate. Composite Häggite/carbon electrodes (Figure S11) were used first to evaluate the insertion mechanisms by cyclic voltammetry, which shows that the storage mechanism for Li and Na cells is mostly faradaic (Figures S12 and S13). ${ }^{54}$ The cycling stability of Häggite and Duttonite was evaluated in galvanostatic mode (C/10 rate) for Li- and Na-based cells (Figure S14): H-Li and H-Na for Häggite-based $\mathrm{Li}$ and $\mathrm{Na}$ batteries respectively, $\mathrm{D}-\mathrm{Li}$ and $\mathrm{D}-\mathrm{Na}$ for Duttonite-based $\mathrm{Li}$ and $\mathrm{Na}$ batteries respectively. The evolution of capacity upon cycling is summarized in Figure 8. The initial $\mathrm{H}-\mathrm{Li}$ and D-Li capacities reach values of 230 and $250 \mathrm{mAh} \cdot \mathrm{g}^{-1}$, respectively $(0.8$ and $1 \mathrm{Li}$ exchanged) comparable to state-of-the-art cells based on vanadium oxy-compounds. ${ }^{17-27}$ However, deterioration occurs during the first 50 cycles for H-Li which stabilizes at $100 \mathrm{mAh} \cdot \mathrm{g}^{-1}$, while a short circuit happens reproductively after 10 to 20 cycles for D-Li. Similar capacity drops also occur with the H-Na and D-Na cells. These behaviors may be ascribed to detrimental dissolution of the electrode material, in agreement with a plateau observed for $\mathrm{H}-\mathrm{Li}$ at high potential (Figure S13a, between $3.5 \mathrm{~V}$ and $4.2 \mathrm{~V}$ vs Li) during the first oxidation step. Moreover, after cycling, when opening the cell, the electrolyte is yellow, characteristic of dissolved decavanadate $\mathrm{V}^{+\mathrm{V}}$ species, well recognized in vanadium oxidebased batteries. ${ }^{55}$ Hence, capacity drop is related to the transformation of the $\mathrm{V}^{+\mathrm{IV}}$ electrode material into soluble $\mathrm{V}^{+\mathrm{V}}$ species. ${ }^{48}$ The occurrence of short circuit with Duttonite (D-Li) may 
be ascribed to the smaller particle size and then increased reactivity compared to Häggite $(\mathrm{H}-$ Li). This dissolution phenomenon for both Häggite and Duttonite, typical of vanadium (oxyhydr)oxides, ${ }^{55}$ may be avoided by increasing the lowest reduction potential or by protecting the nanoparticles surface with conductive carbon coating for instance. ${ }^{17,56,57}$

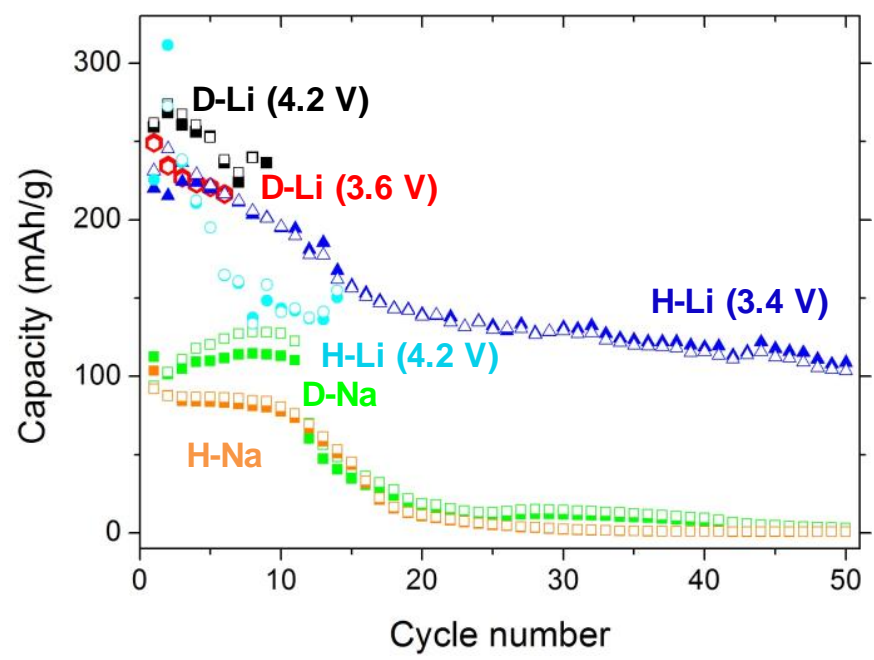

Figure 8. Häggite $(\mathrm{H})$ and Duttonite (D) electrodes cycling stability. Hollow symbols represent charge capacities and solid ones discharge capacities: D-Li (red hexagons and black squares), D-Na (green squares), $\mathrm{H}-\mathrm{Li}$ with a $4.2 \mathrm{~V}$ ( $\left.\mathrm{vs} \mathrm{Li}^{+} / \mathrm{Li}\right)$ highest oxidation potential (blue circles), $\mathrm{H}-\mathrm{Li}$ with a $3.4 \mathrm{~V}$ (vs $\mathrm{Li}^{+} / \mathrm{Li}$ ) highest oxidation potential (blue triangles), and $\mathrm{H}-\mathrm{Na}$ (orange squares).

\section{CONCLUSION}

In this paper, we described a new low temperature aqueous synthetic route towards two poorly studied vanadium oxyhydroxides. Häggite $\mathrm{V}_{2} \mathrm{O}_{3}(\mathrm{OH})_{2}$ and Duttonite $\mathrm{VO}(\mathrm{OH})_{2}$ were obtained at the nanoscale, with sizes at least one order of magnitude smaller than those previously reported in the literature. A combination of techniques enabled confirming that vanadium in Häggite and Duttonite is $\mathrm{V}^{+\mathrm{IV}}$ and obtaining the first insight into the atomic structure of Gains's hydrate $\mathrm{V}_{2} \mathrm{O}_{4} \cdot 2 \mathrm{H}_{2} \mathrm{O}$. This study sheds a new light into the formation mechanisms of vanadium oxyhydroxides, especially Häggite. Gain's hydrate could be 
synthesized selectively and obtained for the first time as nanometer-size ribbons. This phase appears as an important intermediate towards Häggite through topotactic structure transformation. Like many vanadium oxy-compounds, Häggite and Duttonite show interesting electrochemical properties versus insertion but suffer from poor cycling stability, presumably because of dissolution into the battery electrolytes. In the future, the use of smart formulations could avoid this detrimental effect. Nevertheless, Häggite, Duttonite and even Gain hydrate nanoparticles could have interesting properties linked to their semiconductor behavior.

Therefore, this study opens the way to further investigations of the properties of novel $\mathrm{V}^{+\mathrm{IV}}$ (oxyhydr)oxides nanostructures.

\section{EXPERIMENTAL SECTION}

\section{Synthesis}

Sodium metavanadate $\left(\mathrm{NaVO}_{3},>98 \%\right)$, hydrazine dihydrate $\mathrm{H}_{4} \mathrm{~N}_{2} \cdot 2 \mathrm{H}_{2} \mathrm{O}$ (purum, $>98 \%$ ) and concentrated hydrochloric acid (37\% weight ratio) were purchased from Sigma-Aldrich and used as received. Water was purified through a Milli-Q system.

The preparation of oxyhydroxides is a one-step and low temperature $\left(95^{\circ} \mathrm{C}\right)$ procedure conducted as follows: a solution of sodium metavanadate $\left(0.15\right.$ mol. $\mathrm{L}^{-1}$ of vanadium $)$ is prepared in water. The initial $\mathrm{pH}$ is 7.2. 10 equivalents of hydrazine relatively to the amount of vanadium are added. After stirring for 5 minutes, the $\mathrm{pH}$ is adjusted to the final value (4.0 in the case of Duttonite and 3.6-3.8 in the case of Häggite) with concentrated HCl, leading to the precipitation of an amorphous solid. The mixture is then heated at $95{ }^{\circ} \mathrm{C}$ during 4.5 days in an oven (without stirring) or in a thermostatic bath (under stirring). After a few hours, the supernatant reaches its final color, which is colorless in the case of Duttonite and light blue in the case of Häggite. Then, the flask is cooled to ambient temperature and opened. The 
colorless/blue supernatant is discarded and the black powder with a green or red hue (for Duttonite or Häggite, respectively) is washed with water several times by centrifugation until the supernatant $\mathrm{pH}$ is $\sim 6$. Before further characterization, the powders are dried at $40{ }^{\circ} \mathrm{C}$ under vacuum and kept under vacuum to prevent oxidation. Samples with various aging time at $95^{\circ} \mathrm{C}$ were also prepared to study the formation mechanism.

\section{Characterization}

Materials characterization. The as-prepared powders were characterized by powder X-ray diffraction (XRD) using a Brüker D8 X-Ray diffractometer with $\mathrm{Cu} \mathrm{K} \alpha$ radiation (reference ICDD patterns 01-072-1230 and 04-011-6559 for Duttonite and Häggite, respectively), transmission electron microscopy (TEM, Tecnai spirit G2 apparatus operating at $120 \mathrm{kV}$ ), field emission scanning electron microscopy (FESEM, Hitachi S3400-N operating at $5 \mathrm{kV}$ ), thermogravimetric analysis (TGA, NETZSCH STA 409 PC Luxx apparatus) under air, UVvisible-near IR spectroscopy (UV/Vis/NIR Perkin Elmer Lambda 900 with integration sphere), Fourier Transform Infrared spectroscopy (FTIR, Perkin Elmer, Spectrum 400 FTIR/FT-NIR Spectrometer, in the Attenuated Total Reflectance mode using the Universal ATR Sampling Accessory of the constructor) and $\mathrm{N}_{2}$-sorption (BEL Belsorp Max apparatus after outgassing on a BEL Belprep II vacuum apparatus, using the BET model).

$X$ Ray Absorption experiments. XAS experiments were performed at the vanadium K-edge $(5465 \mathrm{eV})$, on the SAMBA beamline of the SOLEIL synchrotron facility operating with a stored current of $72 \mathrm{~mA}$ ( 8 bunches mode) ${ }^{58}$ A cylindrically bendable Pd-coated mirror was used for collimating the beam at the entrance of the fixed exit sagitally focusing $\operatorname{Si}(220)$ double crystal monochromator. A second cylindrically bent Pd-coated mirror was used to focus the beam vertically at the sample position. The grazing incidence of the white and monochromatic beams on both mirrors was set at $8 \mathrm{mrad}$, ensuring an efficient harmonic rejection. Data were recorded in transmission mode by using ionization chambers filled with a 
$\mathrm{N}_{2} / \mathrm{He}$ gas mixture, except for the spectrum of the supernatant solution, obtained by centrifugation of the aliquot extracted from the reaction medium after $1 \mathrm{~h}$ of heating, which was collected in fluorescence mode using a 35-pixel-array Ge detector. The energy calibration was checked by recording simultaneously the spectra of the samples and of a V metallic foil, using a three ionization chambers recording mode. The Extended X-Ray Absorption Fine Structure (EXAFS) gives access to the pseudo radial distribution function, which is linked to the distances between vanadium and its neighboring atoms. The XAS spectra were recorded between 5200 and $6300 \mathrm{eV}$ with an energy step of $2 \mathrm{eV}$ in the extended EXAFS (5560-6300 $\mathrm{eV})$ range, and $0.5 \mathrm{eV}, 0.2 \mathrm{eV}$ and $0.5 \mathrm{eV}$ in the pre-edge, edge (5455-5510 eV) and first EXAFS oscillations (5510-5560 eV) range, respectively. The integration time at each energy point was set to $1 \mathrm{~s}$. The XANES and EXAFS data presented herein were the merged of two spectra and six spectra, respectively. XAS data analysis was carried out using the Athena software package. ${ }^{59}$ The data were calibrated in energy using the maximum of the first derivative of the absorption signal of a metallic vanadium foil recorded simultaneously with the samples. The EXAFS signal, $\chi(\mathrm{k})$, was extracted from the absorption spectrum using a linear pre-edge function and a post-edge background using the Autobk algorithm with a cutoff $\mathrm{R}_{\mathrm{bkg}}=0.8$ and a k-weight $=3$. Pseudo radial distribution Functions (PRDF) were obtained by Fourier Transform of the $\mathrm{k}^{3}$ weighted EXAFS signal between 4.1 and $10.0 \AA^{-1}$ using a dk $=2$ Kaiser-Bessel apodization window. It is noteworthy that PRDF presented in this work are not phase corrected. Therefore, the distances of the main PRDF contributions which are discussed in the text are shifted compared to the real crystallographic distances. EXAFS fitting of distances, coordination numbers and Debye-Waller factors were performed with the Artemis interface to IFeFFIT ${ }^{60}$ using least-squares refinements. The $\mathrm{S}_{0}{ }^{2}$ amplitude reduction parameter which takes into account multielectronic effects and the energy shift $\Delta \mathrm{E}_{0}$ were first determined by fitting $\mathrm{V}_{2} \mathrm{O}_{4}$ on the basis of its crystallographic structure and found equal to 
1.36 and $8.5 \pm 0.3 \mathrm{eV}$ for $\mathrm{E}_{0}=5475.5 \mathrm{eV}$, respectively. ${ }^{61}$ Then both parameters were kept constant to these values during least square fitting of the EXAFS data of the different samples studied herein.

Electrochemical measurements. The electrochemical performances of both oxyhydroxydes were measured using Swagelok cells, assembled in an argon-filled glove box. Lithium metal or sodium metal served as counter electrode (and reference electrode). Two types of electrolyte/working electrode couples were used for the capacity retention study and for the rate performance study. A fiberglass separator (about $2 \mathrm{~mm}$ thick) was soaked by the electrolyte (LP30 for capacity retention study and $\mathrm{LiClO}_{4}$ or $\mathrm{NaClO}_{4} 1 \mathrm{~mol} \cdot \mathrm{L}^{-1}$ in propylene carbonate (PC) for rate performance study). For capacity retention studies, the working electrode was prepared under inert atmosphere by grinding the nanoparticles and Sp Carbon (91:9 weight ratio), followed by deposition of the mixture on the $\mathrm{Al}$ foil. For rate performance studies, a film was prepared and optimized to favor ions and electrons transport by generating porosity inside the percolating working electrode. In that case, the composite working electrode was obtained by coating (Dr Blade technique) on an aluminum foil a slurry of nanoparticles (80\% wt.) with carbon (acetylene black) (15\% wt.), polyvinylidene fluoride (PVDF) (5\% wt.) previously dissolved in N-methylpyrrolidone (NMP) and dibutyl phthalate (DBP) as porogen (NMP:DBP $=60: 40 \%$ vol. and PVDF solution in NMP:DBP at 5\% wt.). After drying at $120^{\circ} \mathrm{C}$ during one hour, the electrodes were pressed at $740 \mathrm{MPa}$ at $120^{\circ} \mathrm{C}$. Finally, the electrodes were soaked in diethyl ether to remove the DBP in order to get a porous electrode. During this study, each rate condition was repeated during three cycles and the third capacity was reported. Cyclic voltammetry and galvanostatic measurements were performed at room temperature on a Biologic multichannel potentiostat. Specific currents were applied, proportional to the mass of active materials. For the capacity retention study, these current correspond to a $\mathrm{C} / 10$ rate $\left(0.1 \mathrm{Li}^{+}\right.$inserted in one hour per vanadium ion). 


\section{ASSOCIATED CONTENT}

Supporting information. Figures S1-S14. This material is available free of charge via the Internet at http://pubs.acs.org.

\section{AUTHOR INFORMATION}

\section{Corresponding Author}

* david.portehault@upmc.fr

\section{Funding Sources}

This work was funded by Rhodia-Solvay as a CIFRE project 


\section{REFERENCES}

(1) Louie, D. K. Handbook of Sulfuric Acid Manufacturing; DKL Engineering, Inc.: Richmond Hill, Canada, 2005.

(2) Abon, M.; Volta, J.-C. Vanadium Phosphorus Oxides for N-Butane Oxidation to Maleic Anhydride. Appl. Catal. A Gen. 1997, 157, 173-193.

(3) Foster, H. B. Vanadium Oxide Catalyst. US-2180353, 1939.

(4) Mamedov, E.; Cortés Corberán, V. Oxidative Dehydrogenation of Lower Alkanes on Vanadium Oxide-Based Catalysts. The Present State of the Art and Outlooks. Appl. Catal. A Gen. 1995, 127, 1-40.

(5) Haber, J. Fifty Years of My Romance with Vanadium Oxide Catalysts. Catal. Today 2009, 142, 100-113.

(6) Wachs, I. E. Catalysis Science of Supported Vanadium Oxide Catalysts. Dalton Trans. 2013, 42, 11762-11769.

(7) Gao, X.; Ba, M. A.; Wachs, I. E. Ethane and N-Butane Oxidation over Supported Vanadium Oxide Catalysts : An in Situ UV-Visible Diffuse Reflectance Spectroscopic Investigation. J. Catal. 1999, 331, 325-331.

(8) Baltes, M. MCM-48-Supported Vanadium Oxide Catalysts, Prepared by the Molecular Designed Dispersion of $\mathrm{VO}(\mathrm{acac})_{2}$ : A Detailed Study of the Highly Reactive MCM-48

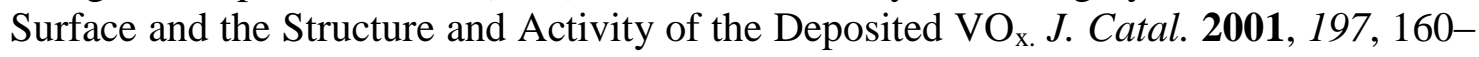
171.

(9) Blasco, T.; Lopez Nieto, J. Oxidative Dehydrogenation of Short Chain Alkanes on Supported Vanadium Oxide Catalysts. Appl. Catal. A Gen. 1997, 157, 117-142.

(10) Chen, K.; Khodakov, A.; Yang, J.; Bell, A.; Iglesia, E. Isotopic Tracer and Kinetic Studies of Oxidative Dehydrogenation Pathways on Vanadium Oxide Catalysts. $J$. Catal. 1999, 333, 325-333.

(11) Mars, P.; van Krevelen, D. W. Oxidations Carried out by Means of Vanadium Oxide Catalysts. Chem. Eng. Sci. 1954, 3, 41-59.

(12) Inomata, M.; Miyamoto, A.; Murakami, Y. Mechanism of the Reaction of Nitric Oxide and Ammonia on Vanadium Oxide Catalyst in the Presence of Oxygen under the Dilute Gas Condition. J. Catal. 1980, 62, 140-148.

(13) Zhu, Z.; Liu, Z.; Liu, S.; Niu, H. A Novel Carbon-Supported Vanadium Oxide Catalyst for NO Reduction with $\mathrm{NH}_{3}$ at Low Temperatures. Appl. Catal. B Environ. 1999, 23, 229-233.

(14) Gómez-Bernal, H.; Cedeño-Caero, L.; Gutiérrez-Alejandre, A. Liquid Phase Oxidation of Dibenzothiophene with Alumina-Supported Vanadium Oxide Catalysts: An Alternative to Deep Desulfurization of Diesel. Catal. Today 2009, 142, 227-233.

(15) Moskalyk, R. R.; Alfantazi, A. M. Processing of Vanadium: A Review. Miner. Eng. 2003, 16, 793-805.

(16) Joerissen, L.; Garche, J.; Fabjan, C.; Tomazic, G. Possible Use of Vanadium RedoxFlow Batteries for Energy Storage in Small Grids and Stand-Alone Photovoltaic Systems. J. Power Sources 2004, 127, 98-104.

(17) Odani, A.; Pol, V. G.; Pol, S. V.; Koltypin, M.; Gedanken, A.; Aurbach, D. Testing Carbon-Coated $\mathrm{VO}_{\mathrm{x}}$ Prepared via Reaction under Autogenic Pressure at Elevated 
Temperature as Li-Insertion Materials. Adv. Mater. 2006, 18, 1431-1436.

(18) Wu, C.; Hu, Z.; Wang, W.; Zhang, M.; Yang, J.; Xie, Y. Synthetic Paramontroseite $\mathrm{VO}_{2}$ with Good Aqueous Lithium-Ion Battery Performance. Chem. Commun. (Camb). 2008, 3891-3893.

(19) Mho, S.; Yeo, I.; Park, S. Hydrothermal Synthesis of $\mathrm{H}_{2} \mathrm{~V}_{3} \mathrm{O}_{8}$ Nanobelts from $\mathrm{V}_{2} \mathrm{O}_{5}$ Xerogels for Lithium Battery Applications. J. Korean Phys. Soc. 2009, 54, 2420-2424.

(20) Xu, Y.; Zheng, L.; Xie, Y. From Synthetic Montroseite VOOH to Topochemical Paramontroseite $\mathrm{VO}_{2}$ and Their Applications in Aqueous Lithium Ion Batteries. Dalton Trans. 2010, 39, 10729-10738.

(21) Wee, G.; Soh, H. Z.; Cheah, Y. L.; Mhaisalkar, S. G.; Srinivasan, M. Synthesis and Electrochemical Properties of Electrospun $\mathrm{V}_{2} \mathrm{O}_{5}$ Nanofibers as Supercapacitor Electrodes. J. Mater. Chem. 2010, 20, 6720.

(22) Wang, F.; Liu, Y.; Liu, C. Hydrothermal Synthesis of Carbon/vanadium Dioxide Coreshell Microspheres with Good Cycling Performance in Both Organic and Aqueous Electrolytes. Electrochim. Acta 2010, 55, 2662-2666.

(23) Li, H.; He, P.; Wang, Y.; Hosono, E.; Zhou, H. High-Surface Vanadium Oxides with Large Capacities for Lithium-Ion Batteries: From Hydrated Aerogel to Nanocrystalline $\mathrm{VO}_{2}(\mathrm{~B}), \mathrm{V}_{6} \mathrm{O}_{13}$ and $\mathrm{V}_{2} \mathrm{O}_{5}$. J. Mater. Chem. 2011, 21, 10999.

(24) Armstrong, a R.; Lyness, C.; Panchmatia, P. M.; Islam, M. S.; Bruce, P. G. The Lithium Intercalation Process in the Low-Voltage Lithium Battery Anode $\mathrm{Li}_{(1+\mathrm{x})} \mathrm{V}_{(1-}$ х) $\mathrm{O}_{2}$. Nat. Mater. 2011, 10, 223-229.

(25) Sun, Y.; Jiang, S.; Bi, W.; Wu, C.; Xie, Y. Highly Ordered Lamellar $\mathrm{V}_{2} \mathrm{O}_{3}$-Based Hybrid Nanorods towards Superior Aqueous Lithium-Ion Battery Performance. $J$. Power Sources 2011, 196, 8644-8650.

(26) Hamani, D.; Ati, M.; Tarascon, J.-M.; Rozier, P. $\mathrm{Na}_{\mathrm{x}} \mathrm{VO}_{2}$ as Possible Electrode for NaIon Batteries. Electrochem. commun. 2011, 13, 938-941.

(27) Chen, Z.; Augustyn, V.; Jia, X.; Xiao, Q.; Dunn, B.; Lu, Y. High-Performance SodiumIon Pseudocapacitors Based on Hierarchically Porous Nanowire Composites. ACS Nano 2012, 6, 4319-4327.

(28) Manning, T. D.; Parkin, I. P.; Clark, R. J. H.; Sheel, D.; Pemble, M. E.; Vernadou, D. Intelligent Window Coatings: Atmospheric Pressure Chemical Vapour Deposition of Vanadium Oxides. J. Mater. Chem. 2002, 12, 2936-2939.

(29) Livage, J.; Ganguli, D. Sol-gel Electrochromic Coatings and Devices: A Review. Sol. Energy Mater. Sol. Cells 2001, 68, 365-381.

(30) Wu, C.; Feng, F.; Xie, Y. Design of Vanadium Oxide Structures with Controllable Electrical Properties for Energy Applications. Chem. Soc. Rev. 2013, 42, 5157-5183.

(31) Sun, Y.; Jiang, S.; Bi, W.; Long, R.; Xiaogang, W.; Wu, C.; Wei, S.; Xie, Y. New Aspects of Size-Dependent Metal-Insulator Transition in Synthetic Single-Domain Monoclinic Vanadium Dioxide Nanocrystals. Nanoscale 2011, 3, 4394-4401.

(32) Evans, H. T.; Mrose, M. E. The Crystal Structures of Three New Vanadium Oxide Minerals. Acta Crystallogr. 1958, 11, 56-58.

(33) Thompson, M.; Roach, C.; Meyrowitz, R. Duttonite, a New Quadrivalent Vanadium Oxide from the Peanut Mine, Montrose County, Colorado. Am. Mineral. 1957, 42, 455-460. 
(34) Schwarzmann, E. Synthese von Duttonit $\mathrm{VO}(\mathrm{OH})_{2}$. Z. Naturforsch 1970, 25b, 14851486.

(35) Bak, R. Synthesis of Duttonite. Taehan Hwahakhoe Chi 1973, 17, 424-427.

(36) Glemser, O.; Schwarzmann, E. Lower Vanadium Hydroxides. Z.Anorg.Allg.Chem 1955, 249-255.

(37) Wu, C.; Dai, J.; Zhang, X.; Yang, J.; Xie, Y. Synthetic Haggite $\mathrm{V}_{4} \mathrm{O}_{6}(\mathrm{OH})_{4}$ Nanobelts: Oxyhydroxide as a New Catalog of Smart Electrical Switch Materials. J. Am. Chem. Soc. 2009, 131, 7218-7219.

(38) Pommer, A. M. Reduction of Quinquavalent Vanadium Solutions by Wood and Lignite. Geochim. Cosmochim. Acta 1957, 13, 20-27.

(39) Srivastava, V. C. Hydrogen Absorption in Vanadium Pentoxide. Mater. Res. Bull. 1988, 23, 341-348.

(40) Cesbron, F.; Vachey, H. La Lenoblite, Nouvel Oxyde Hydraté de Vanadium (IV). Bull. Soc. Fr. Minéral. Cristal. 1970, 93, 235-241.

(41) Théobald, F. Contribution à L'étude Des Oxydes et Hydrates D'oxydes de Vanadium Aux Derés D'oxydation IV, V et Intermédiaires, Université de Besançon, 1975.

(42) Nakamoto, K. Inrganic and Coordination Compounds - Part A; Wiley \& Sons, Inc.: New York, 2009.

(43) Nakamoto, K. Infrared and Raman Spectra of Inrganic and Coordination Compounds Part B; Wiley \& Sons, Inc.: New York, 2009.

(44) Bai, L.; Gao, Y.; Li, W.; Luo, H.; Jin, P. Synthesis and Atmospheric Instability of Well Crystallized Rod-Shaped V 2 O 4• 2H 2 O Powders Prepared in an Aqueous Solution. J. Ceram. Soc. Japan 2008, 116, 395-399.

(45) Theobald, F. Contribution à L'étude Des Oxydes et Hydrates D'oxydes Du Vanadium Aux Degrés D'oxydation IV, V et Intermédiaires, Université de Besançon, 1975.

(46) Wong, J.; Lytle, F.; Messmer, R.; Maylotte, D. K-Edge Absorption Spectra of Selected Vanadium Compounds. Phys. Rev. B 1984, 30, 5595-5610.

(47) Chaurand, P.; Rose, J.; Briois, V.; Salome, M.; Proux, O.; Nassif, V.; Olivi, L.; Susini, J.; Hazemann, J.; Bottero, J. New Methodological Approach for the Vanadium K-Edge X-Ray Absorption Near-Edge Structure Interpretation: Application to the Speciation of Vanadium in Oxide Phases from Steel Slag. J. Phys. Chem. B 2007, 111, 5101-5110.

(48) Jaber, M.; Ribot, F.; Binet, L.; Briois, V.; Cassaignon, S.; Rao, K. J.; Livage, J.; Steunou, N. Ex Situ X-Ray Diffraction, X-Ray Absorption Near Edge Structure, Electron Spin Resonance, and Transmission Electron Microscopy Study of the Hydrothermal Crystallization of Vanadium Oxide Nanotubes: An Insight into the Mechanism of Formation. J. Phys. Chem. C 2012, 116, 25126-25136.

(49) Jolivet, J.-P. De La Solution à L'oxyde; CNRS Editions: Paris, 1994.

(50) Molinaro, F.; Ibers, J. Crystal and Molecular Structure of 2, 3, 7, 8, 12, 13, 17, 18Octaethylporphinatooxovanadium (IV). Inorg. Chem. 1976, 15, 2278-2283.

(51) Anderson, S.; Sundholm, A.; Magnéli, A. A Homologous Series of Mixed Titanium Chromium Oxides $\mathrm{Ti}_{\mathrm{n}-2} \mathrm{Cr}_{2} \mathrm{O}_{2 \mathrm{n}-1}$ Isomorphous with the Series $\mathrm{Ti}_{\mathrm{n}} \mathrm{O}_{2 \mathrm{n}-1}$ and $\mathrm{V}_{\mathrm{n}} \mathrm{O}_{2 \mathrm{n}-1}$. Acta Chem. Scand. 1959, 13, 989-997.

(52) Portehault, D.; Maneeratana, V.; Candolfi, C.; Oeschler, N.; Veremchuk, I.; Grin, Y.; Sanchez, C.; Antonietti, M. Facile General Route toward Tunable Magnéli 
Nanostructures and Their Use as Thermoelectric Metal Oxide / Carbon Nanocomposites. ACS Nano 2011, 5, 9052-9061.

(53) Maneeratana, V.; Portehault, D.; Chaste, J.; Mailly, D.; Antonietti, M.; Sanchez, C. Original Electrospun Core - Shell Nanostructured Magnéli Titanium Oxide Fibers and Their Electrical Properties. Adv. Mater. 2014, 26, 2654-2658.

(54) Lindström, H.; Södergren, S.; Solbrand, A.; Rensmo, H.; Lindquist, S. E. Li+ Ion Insertion in $\mathrm{TiO} 2$ (anatase). 2. Voltammetry on Nanoporous Films. J. Phys. Chem. B 1997, 97, 7717-7722.

(55) Sudant, G. Synthèse, Caractérisation et Propriétés électrochimiques vis-à-vis Du Lithium D'oxydes Divisés à Base de Vanadium et de Titane, Université de Picardie Jules Verne, 2004.

(56) Wang, X.; Huang, Y.; Jia, D.; Pang, W. K.; Guo, Z.; Du, Y.; Tang, X.; Cao, Y. SelfAssembled Sandwich-like Vanadium Oxide/Graphene Mesoporous Composite as High-Capacity Anode Material for Lithium Ion Batteries. Inorg. Chem. 2015, 54, 11799-11806.

(57) Wang, X.; Jia, W.; Wang, L.; Huang, Y.; Guo, Y.; Sun, Y.; Jia, D.; Pang, W.; Guo, Z.; Tang, X. Simple in situ synthesis of carbon-supported and nanosheet-assembled vanadium oxide for ultra-high rate anode and cathode materials of lithium ion batteries. J. Mater. Chem. A 2016, 4, 13907-13915

(58) Briois, V.; Fonda, E.; Belin, S.; Barthe, L.; La Fontaine, C.; Langlois, F.; Ribbens, M.; Villain, F. SAMBA: The 4-40 keV X-Ray Absorption Spectroscopy Beamline at SOLEIL. UVX 2010 - 10e Colloq. sur les Sources Cohérentes Incohérentes UV, VUV X; Appl. Développements Récents 2011, 2010, 41-47.

(59) Ravel, B.; Newville, M. ATHENA, ARTEMIS, HEPHAESTUS: Data Analysis for XRay Absorption Spectroscopy Using IFEFFIT. J. Synchrotron Radiat. 2005, 12, 537541.

(60) Newville, M. IFEFFIT: Interactive XAFS Analysis and FEFF Fitting. J. Synchrotron Rad. 2001, 8, 322-324.

(61) Longo, J. M.; Kierkegaard, P. A Refinement of the Structure of $\mathrm{VO}_{2}$. Acta Chem. Scand. 1970, 24, 420-426. 


\section{Supplementary Information}

\section{Nanoparticles of low valence vanadium oxyhydroxides: reaction mechanisms and}

polymorphism control by low temperature aqueous chemistry

Julie Besnardiere, ${ }^{1}$ Xavier Petrissans, ${ }^{2}$ François Ribot, ${ }^{1}$ Valérie Briois, ${ }^{3}$ Christine Surcin, ${ }^{4}$ Matthieu Morcrette, ${ }^{4}$ Valérie Buissette, ${ }^{5}$ Thierry Le Mercier, ${ }^{5}$ Sophie Cassaignon, ${ }^{1}$ David Portehault $^{1, *}$

${ }^{1}$ Sorbonne Universités UPMC Univ Paris 06 - CNRS - Collège de France, UMR 7574 Chimie de la Matière Condensée de Paris, 4 place Jussieu, 75252 Paris Cedex 05, France

${ }^{2}$ Institut de Recherche de Chimie Paris, UMR CNRS 8247, Chimie ParisTech, 11 rue Pierre et Marie Curie, 75005 Paris, France

${ }^{3}$ Synchrotron SOLEIL, L'Orme des Merisiers, Saint-Aubin - BP 48, Gif-sur-Yvette F-91192, France.

${ }^{4}$ Université de Picardie Jules Verne - CNRS - Réseau sur le Stockage Electrochimique de l'Energie (RS2E), UMR 7314 Laboratoire de Réactivité des Solides, 33 Rue Saint Leu, 80039 Amiens Cedex (France).

${ }^{5}$ RHODIA-Solvay, Centre de Recherches d'Aubervilliers, 52 rue de la Haie-Coq, 93308 Aubervilliers Cedex, France.

Corresponding author: david.portehault@upmc.fr 


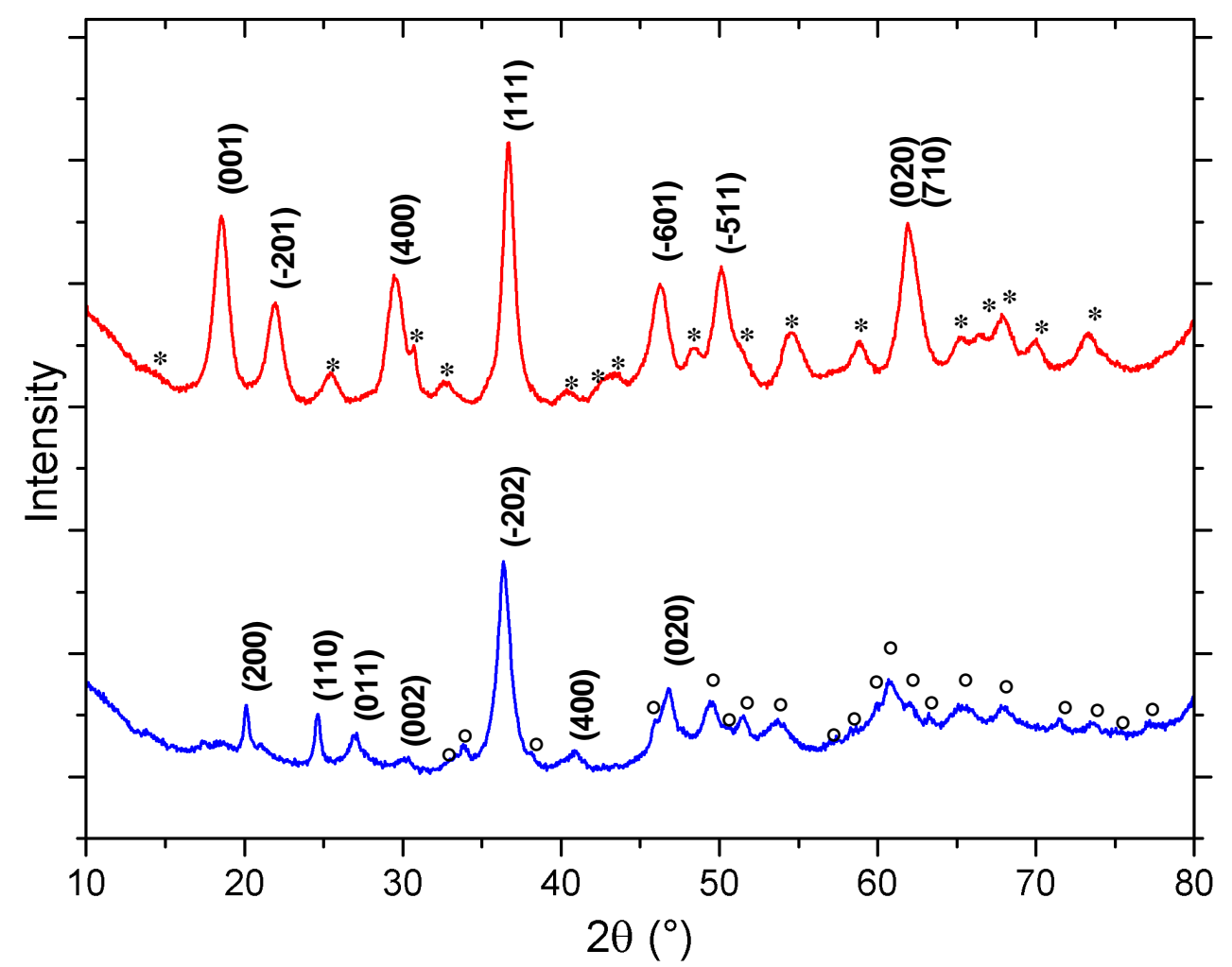

Figure S1 XRD diagrams of Häggite (red) and Duttonite (blue). Peaks corresponding to Häggite (stars) and Duttonite (circles). The main peaks for both phases are indexed.

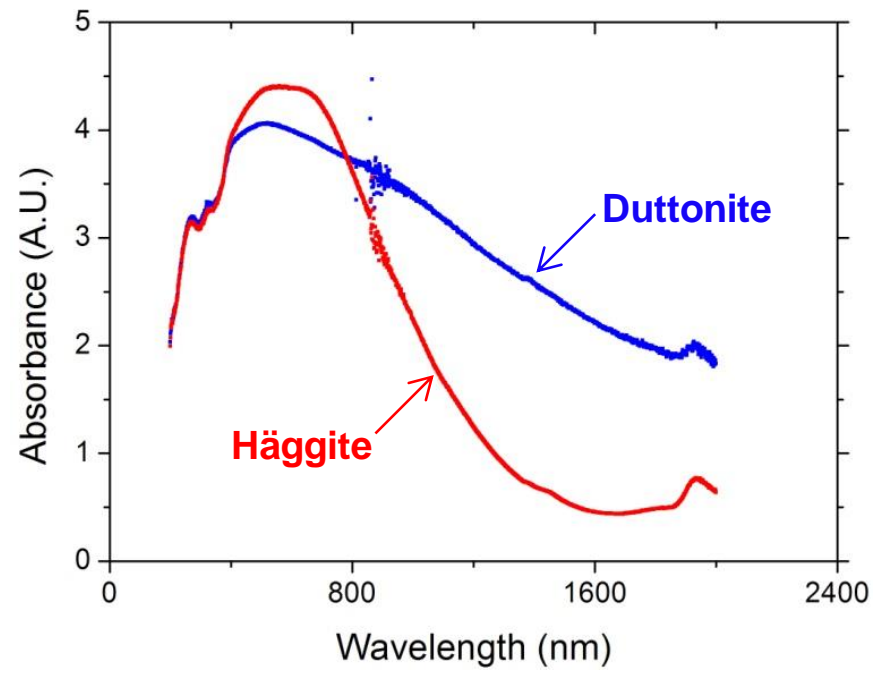

Figure S2 UV-visible-NIR spectra of Häggite (red) and Duttonite (blue) calculated from reflectance measurements. 


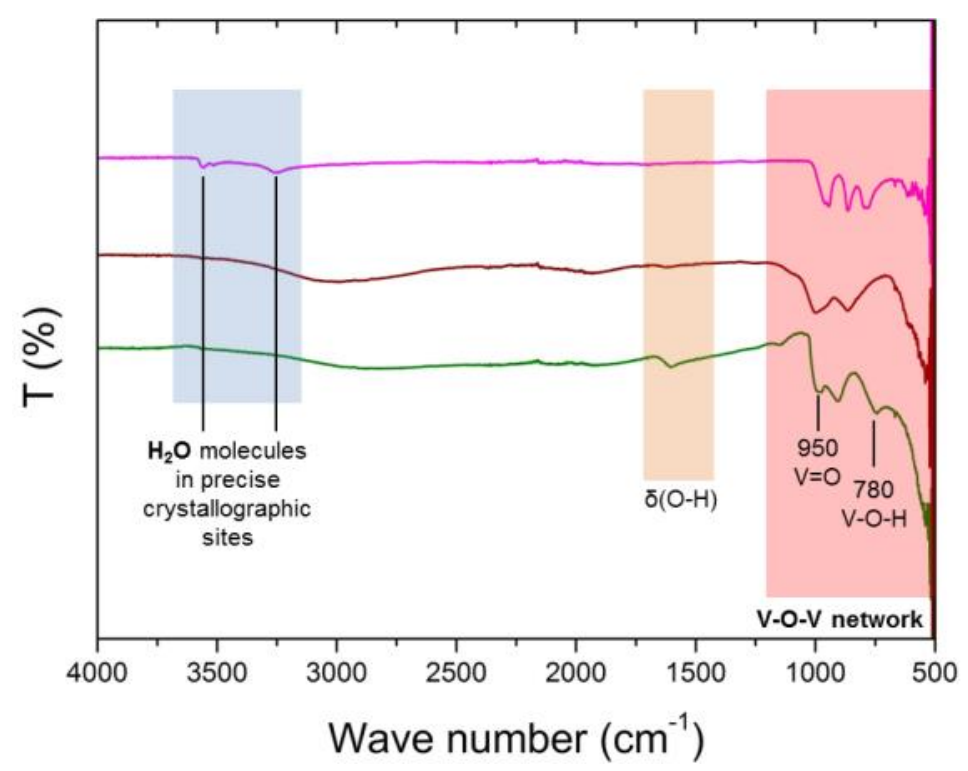

Figure S3 FTIR transmission spectra of Duttonite (green), Häggite (red) and Gain's hydrate $\mathrm{V}_{2} \mathrm{O}_{4} \cdot 2 \mathrm{H}_{2} \mathrm{O}$ (pink). The main vibrational bands are indexed according to ref $41-43$ and Socrates, G. Infrared and Raman Characteristic Group Frequencies; Wiley \& Sons, Inc.: New York, 2001..

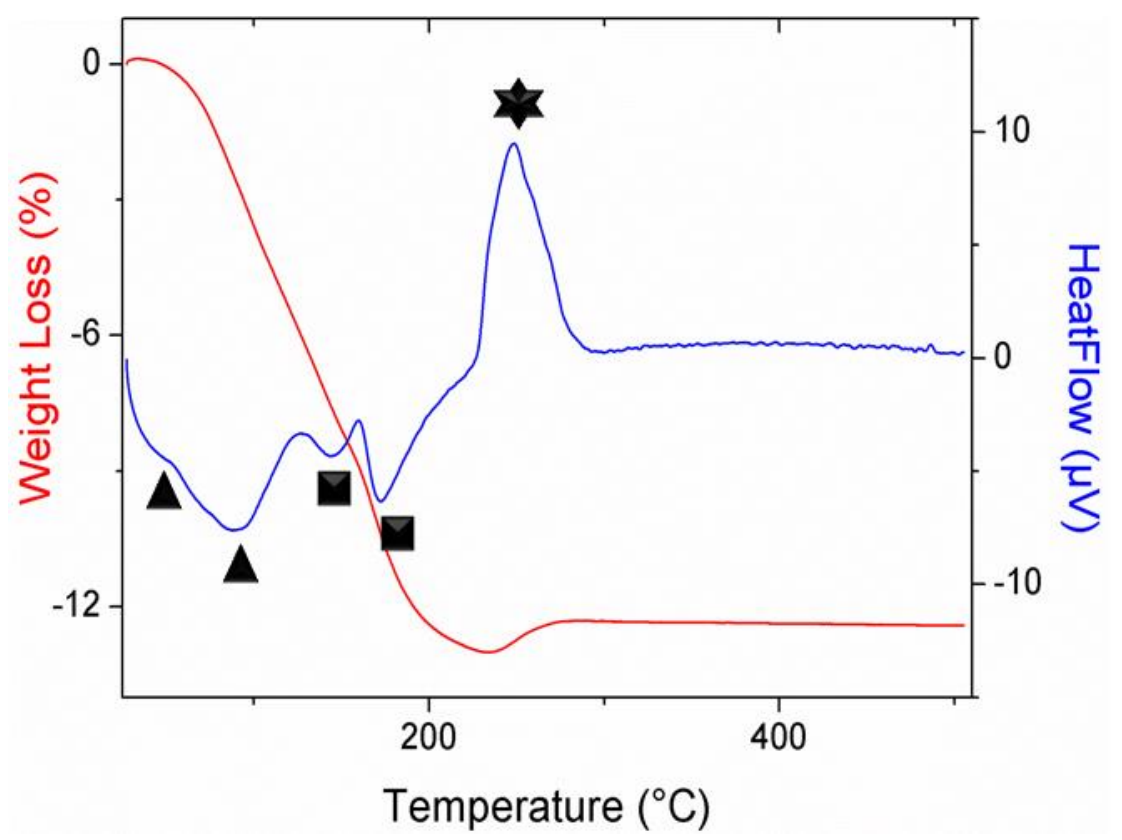

Figure S4 Häggite TGA (left, red) TDA (blue, right) traces recorded at a $2{ }^{\circ} \mathrm{C} \cdot \mathrm{min}^{-1}$ sweep rate. Water desorption, structural water elimination and oxidation are indicated respectively by triangles, squares and stars. 


\section{a}
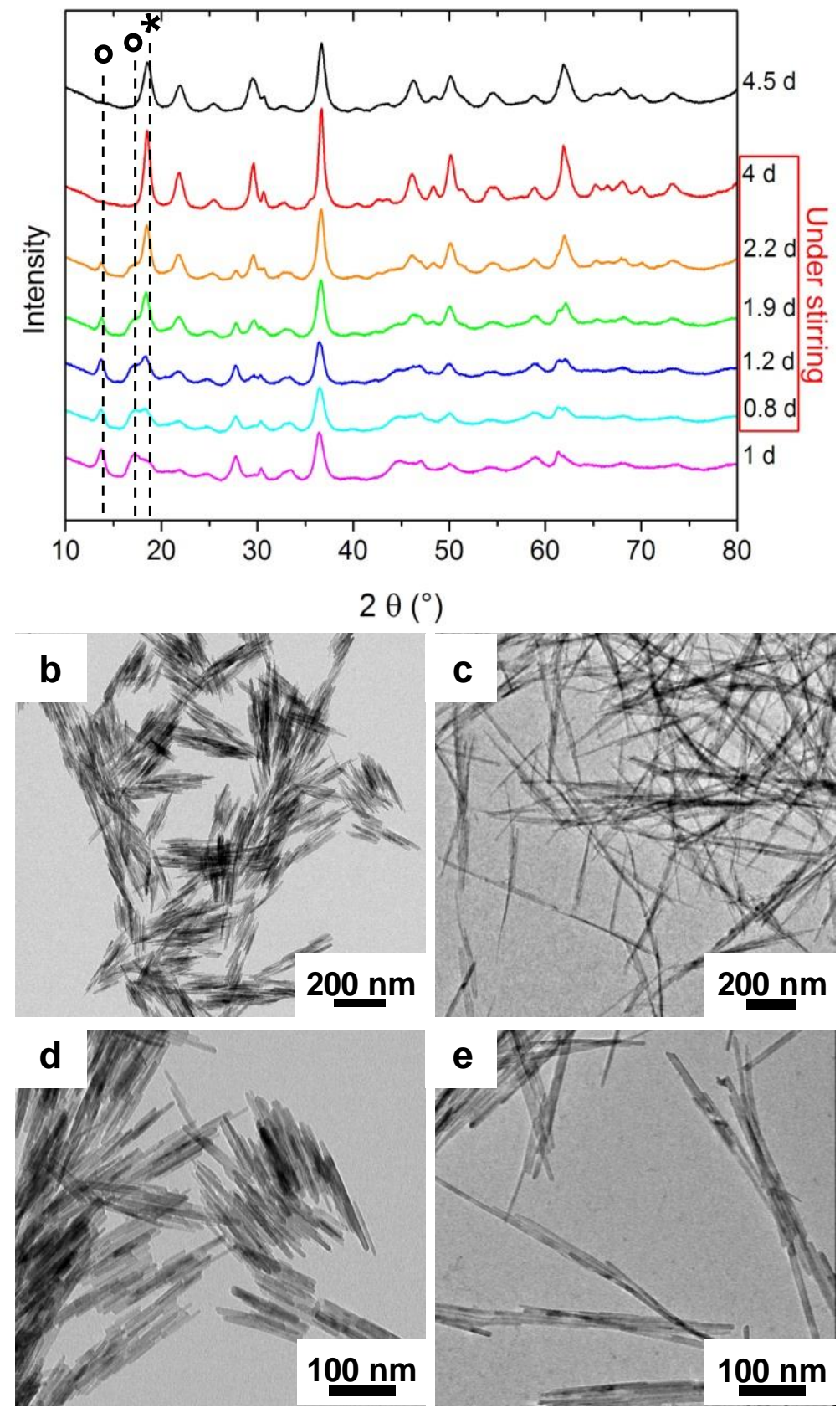

Figure S5. Effect of stirring on the reaction rate and on the morphology of Häggite particles. (a) XRD patterns of the samples isolated after a given time at $95{ }^{\circ} \mathrm{C}$. Circles $\left({ }^{\circ}\right)$ and stars $(*)$ indicates Gain's hydrate and Häggite characteristic peaks, respectively. (b-e) TEM pictures of the final product (Häggite particles) obtained after $4 \mathrm{~d}$ under stirring ( $b$ and d) or after $4.5 \mathrm{~d}$ without stirring (c and e). 
Table S1 Geometry of vanadium coordination polyhedra in references and synthesized compounds, according to Wong et al. ${ }^{46}$ and ICDD data $\left(\mathrm{V}_{2} \mathrm{O}_{3}\right.$ : 04-004-2833; $\mathrm{V}_{2} \mathrm{O}_{4}$ : 04-0032035; $\mathrm{V}_{2} \mathrm{O}_{5}$ : 04-008-8273; $\mathrm{VOSO}_{4} .3 \mathrm{H}_{2} \mathrm{O}$ : 04-010-1684; Duttonite: 01-072-1230; $\mathrm{NaVO}_{3}$ anhydrous: 04-013-7267; Häggite: 04-011-6559).

\begin{tabular}{|c|c|c|c|}
\hline Compound & Oxidation state & $\begin{array}{l}\text { Coordination } \\
\text { number }\end{array}$ & Site features \\
\hline $\mathrm{V}_{2} \mathrm{O}_{3}$ & + III & 6 & Distorted octahedron (1.96 and $2.06 \AA$ ) \\
\hline $\mathrm{V}_{2} \mathrm{O}_{4}$ & $+\mathrm{IV}$ & 6 & $\begin{array}{l}\text { V shifted from the octahedron center } \\
\qquad\left(d_{\text {short }}=1.76 \AA\right)\end{array}$ \\
\hline $\mathrm{V}_{2} \mathrm{O}_{5}$ & $+\mathrm{V}$ & 5 & Square pyramid (1.59 et $1.78-2.02 \AA)$ \\
\hline $\operatorname{VOSO}_{4} \cdot 3 \mathrm{H}_{2} \mathrm{O}$ & $+\mathrm{IV}$ & 6 & $\begin{array}{c}\text { Octahedron } \\
\text { (3 different distances } \mathrm{V}=\mathrm{O}(1.57 \AA), \mathrm{V}-\mathrm{O} \\
\left.(2.0 \AA) \text { et } \mathrm{V}-\mathrm{OH}_{2}(2.28 \AA)\right)\end{array}$ \\
\hline Duttonite $\mathrm{VO}(\mathrm{OH})_{2}$ & $+\mathrm{IV}$ & 5 & $\begin{array}{c}\text { Distorted octahedron (3 different distances } \\
\text { from } 1.82 \text { to } 2.06 \AA)\end{array}$ \\
\hline $\mathrm{NaVO}_{3}$ anhydrous & $+\mathrm{V}$ & 4 & Tetrahedron ( 1.66 et $1.81 \AA$ ) \\
\hline $\begin{array}{c}\mathrm{NaVO}_{3}(\mathrm{aq}) \\
{[0.15 \mathrm{M} ; \mathrm{pH} 7.2]}\end{array}$ & $+\mathrm{V}$ & 4 & Tetrahedron (metavanadate) \\
\hline $\begin{array}{l}\text { Gain's hydrate } \\
\mathrm{V}_{2} \mathrm{O}_{4} \cdot 2 \mathrm{H}_{2} \mathrm{O}\end{array}$ & $+\mathrm{IV}$ & $?$ & Unsolved structure $^{1}$ \\
\hline Häggite & $\begin{array}{l}+ \text { IV (confirmed in } \\
\text { the present work) }\end{array}$ & 6 & $\begin{array}{c}\text { Distorted octahedron (4 different distances } \\
\text { from } 1.82 \text { to } 2.06 \AA \text { ) }\end{array}$ \\
\hline
\end{tabular}

\footnotetext{
${ }^{1}$ The coordination polyhedron is non-centrosymetric because the presence of $\mathrm{V}=\mathrm{O}, \mathrm{V}-\mathrm{O}-\mathrm{V}$ and $\mathrm{V}-\mathrm{O}-\mathrm{H}$ bonds was attested by IR spectroscopy.
} 
a

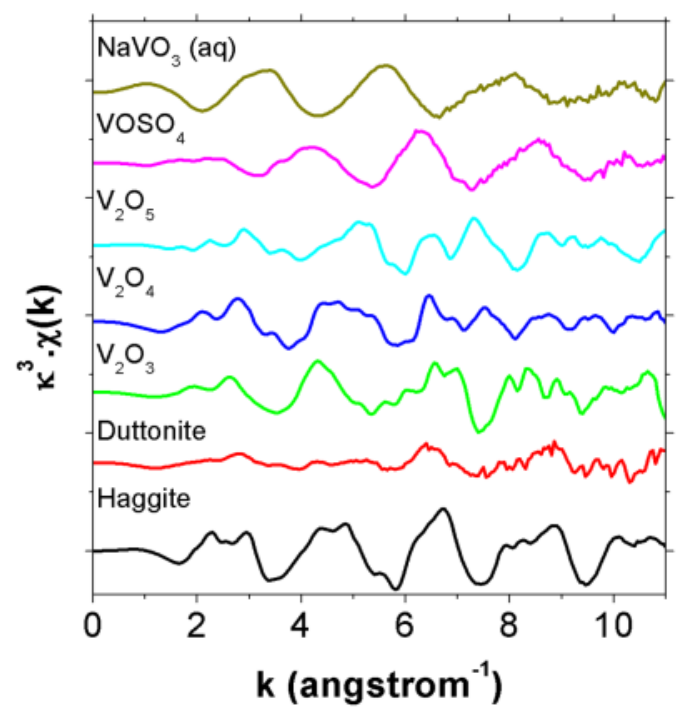

$\mathbf{b}_{40}$

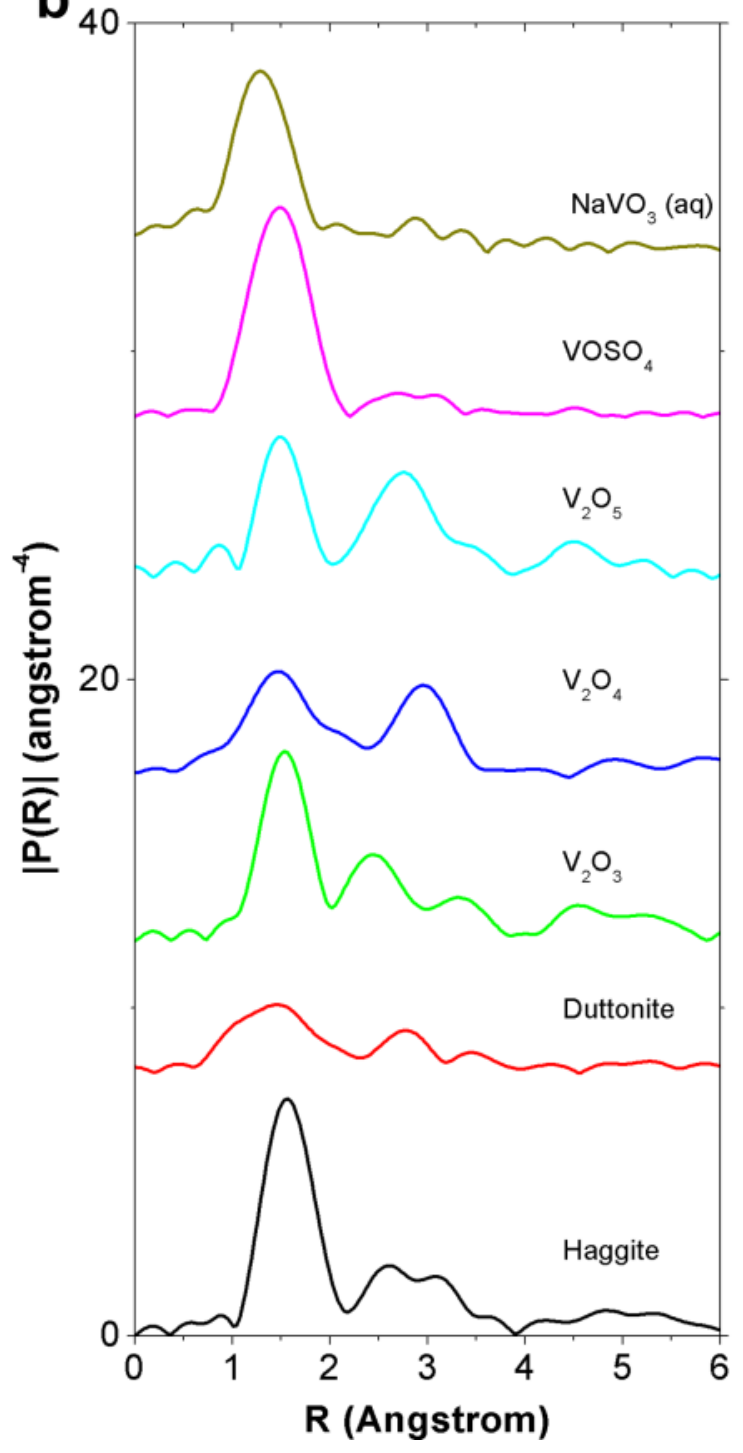

Figure S6. Treatment of the EXAFS spectra $\left(\mathrm{V}_{2} \mathrm{O}_{3}\right.$ in green, $\mathrm{V}_{2} \mathrm{O}_{4}$ in orange; $\mathrm{V}_{2} \mathrm{O}_{5}$ in blue; $\mathrm{VOSO}_{4} \cdot 3 \mathrm{H}_{2} \mathrm{O}$ in purple; Duttonite in red; $\mathrm{NaVO}_{3}$ in black and Häggite in grey). (a) $\mathrm{k}^{3 *} \chi(\mathrm{k})$ plotted as a function of k. (b) Radial distribution function obtain through a Fourier transform of (a), giving access to distances to the first neighbors. Several coordination spheres are observed, depending on the compound. The distances to the first neighbors are coherent with the geometry of the coordination polyhedra: it increases from $\mathrm{V}^{\mathrm{V}}$ tetrahedra in $\mathrm{NaVO}_{3}$, to pyramidal and then octahedral coordinations $\left(\mathrm{V}_{2} \mathrm{O}_{3}\right.$ and Häggite). 

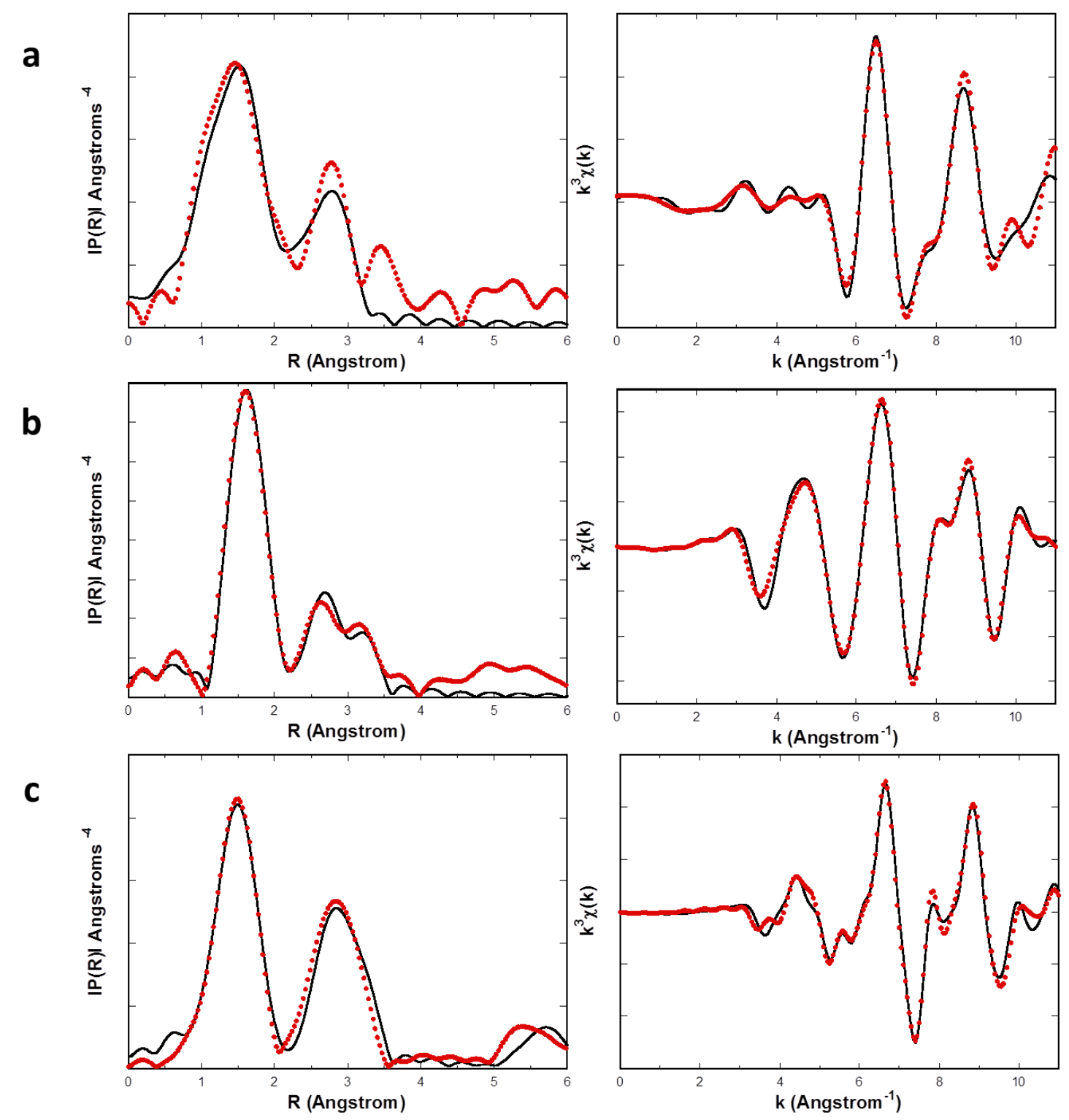

Figure S7. Results of least square fittings: Comparison of the magnitude of the PRDF (left) and real part of the EXAFS spectrum (right) for (a) Duttonite, (b) Häggite and (c) Gain's hydrate. Red dots: experimental data. Black lines: fits 
Table S2 Refined structural parameters for Duttonite, Häggite and Gain's Hydrate from least square fitting of the EXAFS spectra recorded at the V K edge. The coordination numbers were held fixed at the values corresponding to the respective structures, while $\mathrm{R}$ and $\sigma$ were allowed to vary. $\mathrm{S}_{0}{ }^{2}$ was determined to be 1.36 on $\mathrm{V}_{2} \mathrm{O}_{4}$ and was kept at this value for the fitting of those phases, $\Delta \mathrm{E}_{0}$ was also fixed at. $8.5 \pm 0.3 \mathrm{eV}$ for $\mathrm{E}_{0}=5475.5 \mathrm{eV}$. Fit were performed on R-space for Fourier Transforms of the EXAFS spectra carried out in the 4.1$10.0 \AA^{-1} \mathrm{k}$-range. The R-factor measures the relative misfit with respect to the experimental data.

\begin{tabular}{|c|c|c|c|c|}
\hline Backscatterer & $N$ & $\mathbf{R}(\AA)$ & $\sigma^{2}\left(\AA^{2}\right) \times 10^{3}$ & R-factor \\
\hline \multicolumn{5}{|c|}{ Duttonite } \\
\hline $\mathrm{O}$ & 1.0 & $1.64 \pm 0.05$ & $7.2 \pm 6.6$ & \multirow{4}{*}{0.0197} \\
\hline O & 4.0 & $1.99 \pm 0.08$ & $22.1 \pm 9.8$ & \\
\hline $\mathrm{O}$ & 1.0 & $2.38 \pm 0.26$ & $19.7 \pm 52.7$ & \\
\hline V & 1.0 & $3.09 \pm 0.07$ & $3.89 \pm 24.8$ & \\
\hline \multicolumn{5}{|c|}{ Häggite } \\
\hline $\mathrm{O}$ & 1.0 & $1.69 \pm 0.03$ & $8.2 \pm 5.0$ & \multirow{5}{*}{0.0171} \\
\hline O & 5.0 & $2.01 \pm 0.01$ & $8.7 \pm 1.6$ & \\
\hline V & 2.0 & $3.07 \pm 0.31$ & $13.4 \pm 17.5$ & \\
\hline V & 2.0 & $3.17 \pm 0.36$ & $21.4 \pm 105$ & \\
\hline $\mathrm{V}$ & 1.0 & 3.37 & $2.4 \pm 6.4$ & \\
\hline \multicolumn{5}{|c|}{ Gain's hydrate } \\
\hline O & 1.0 & $1.64 \pm 0.01$ & $5.2 \pm 1.5$ & \multirow{6}{*}{0.0311} \\
\hline O & 4.0 & $2.01 \pm 0.01$ & $14.5 \pm 2.0$ & \\
\hline O & 1.0 & $2.29 \pm 0.07$ & $16.2 \pm 11.0$ & \\
\hline V & 2.0 & $3.08 \pm 0.02$ & $16.0 \pm 3.0$ & \\
\hline $\mathrm{V}$ & 1.0 & $3.40 \pm 0.01$ & $3.3 \pm 1.7$ & \\
\hline $\mathrm{V}$ & 2.0 & $5.97 \pm 0.04$ & $9.4 \pm 6.3$ & \\
\hline
\end{tabular}


a

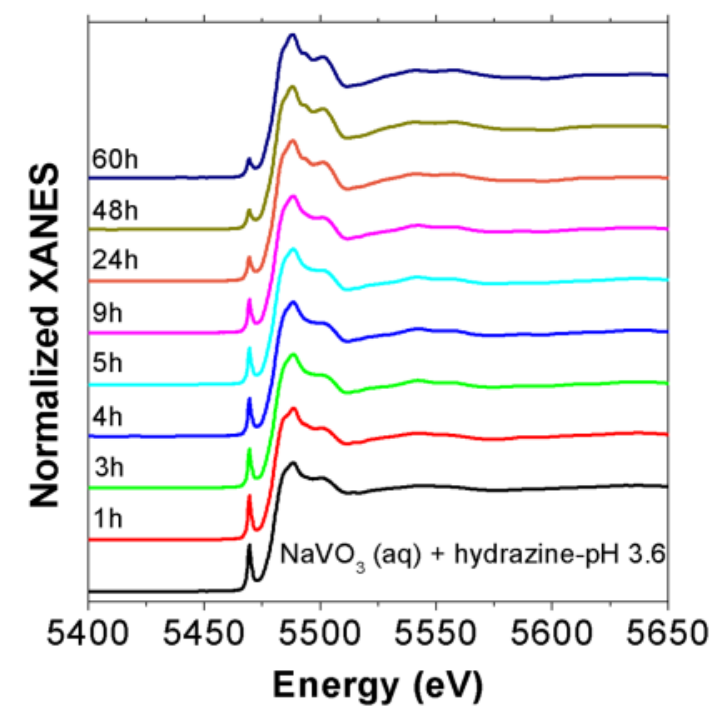

b

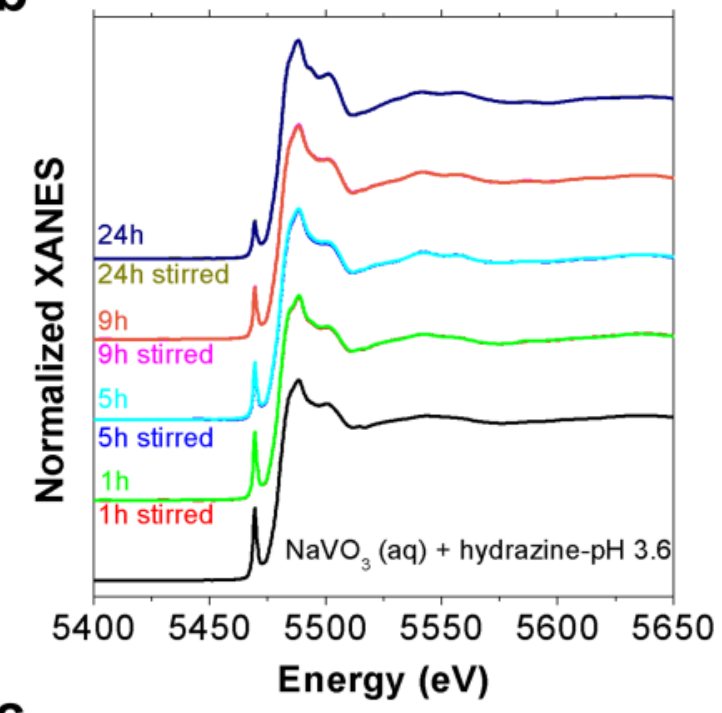

C

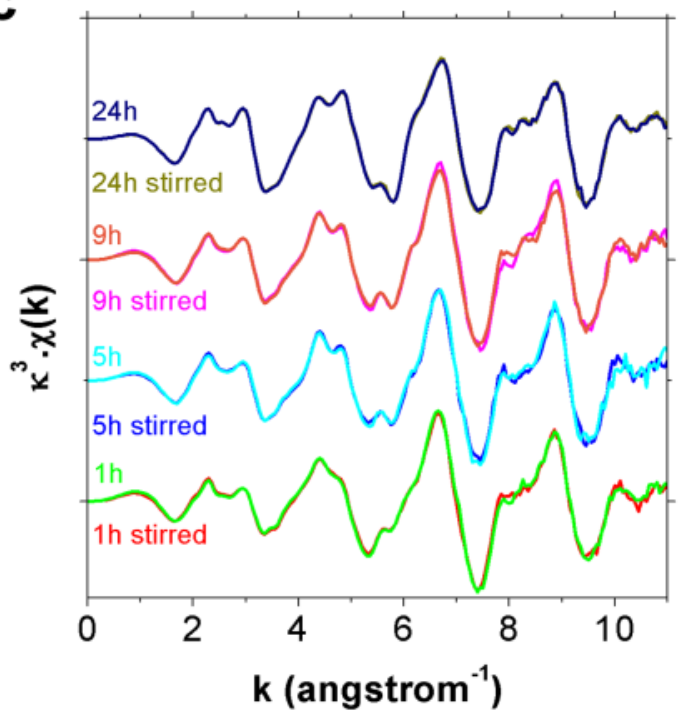

Figure S8. (a) XAS spectra of the samples obtained under non-stirred conditions at different reaction times. Comparisons of (b) XAS spectra and (c) $\mathrm{k}^{3} * \chi(\mathrm{k})=\mathrm{f}(\mathrm{k})$ plots for stirred and nonstirred conditions at given reaction times, showing that the stirring conditions do not change significantly structural features. 


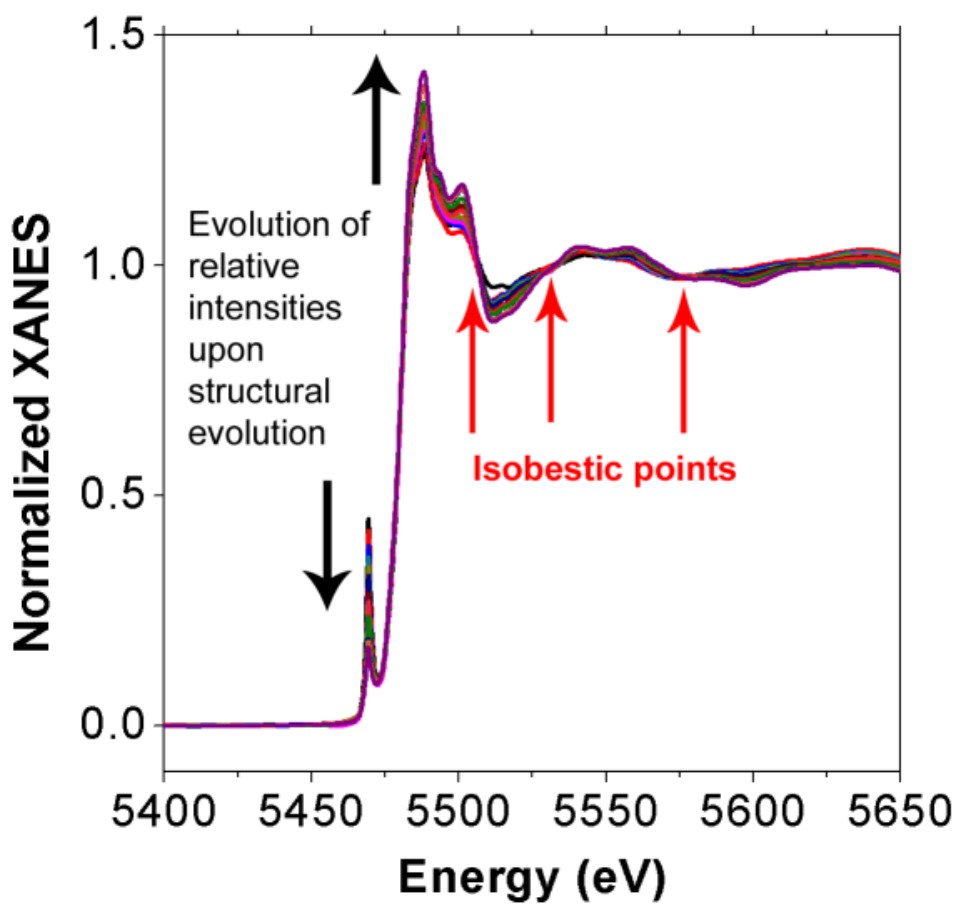

Figure S9. XAS kinetic study of Häggite crystallization at $95{ }^{\circ} \mathrm{C}$ under stirring. The solid samples are isolated from the reaction medium at each reaction time, from $1 \mathrm{~h}$ to 6.5 days. (a) XAS spectra. 


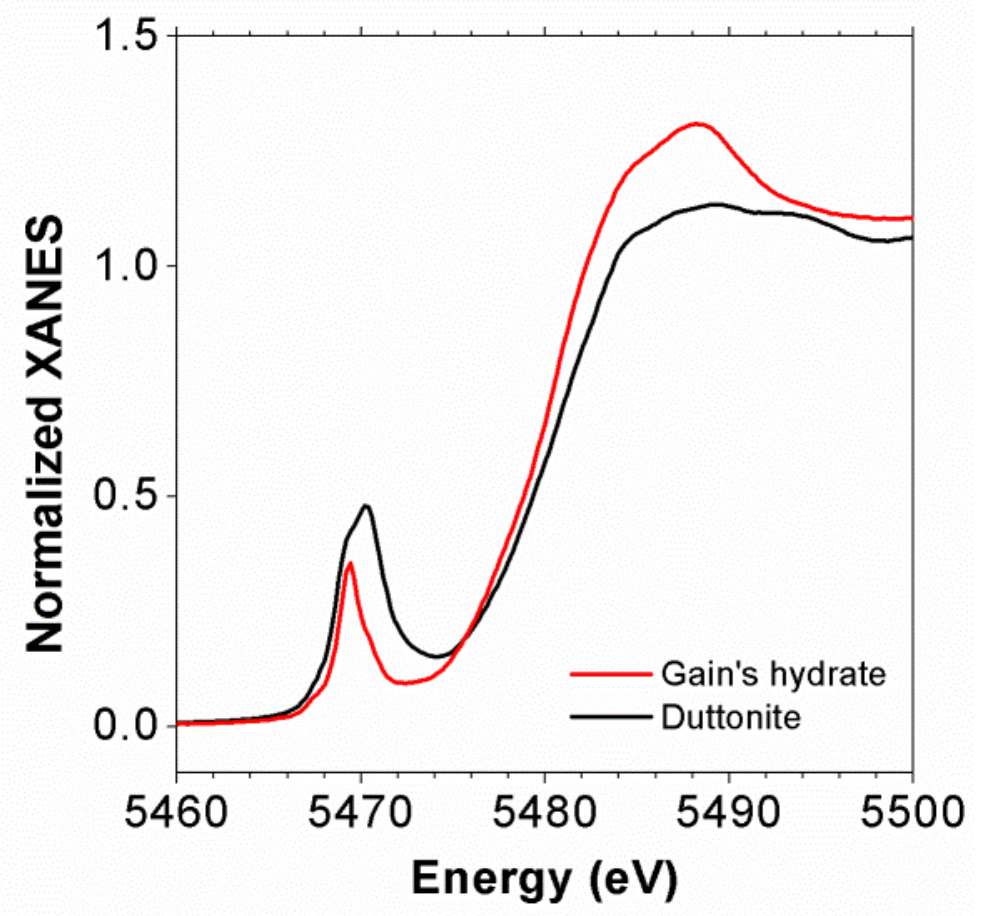

Figure S10. Pre-edge area of the XAS spectra for Duttonite and Gain's Hydrate (sample under non-stirring conditions after $5 \mathrm{~h}$ heating).
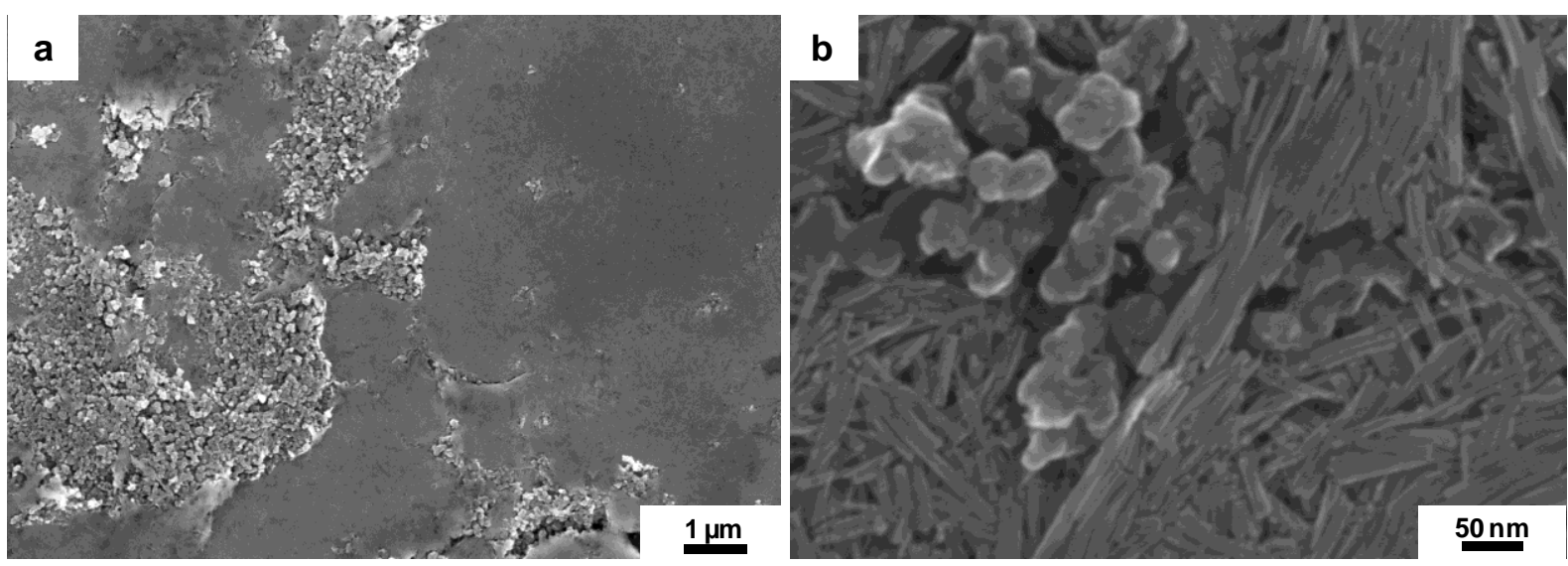

Figure S11. SEM-FEG picture of the Häggite electrode showing a good mixing between spherical conductive carbon and Häggite rods. 
a

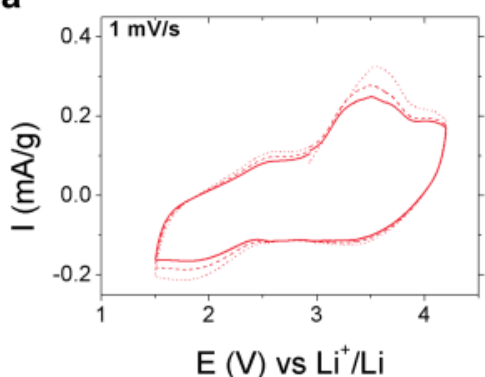

C

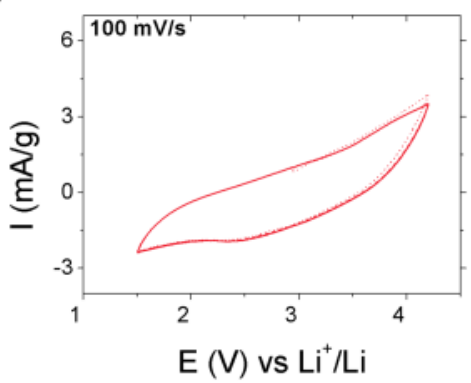

b

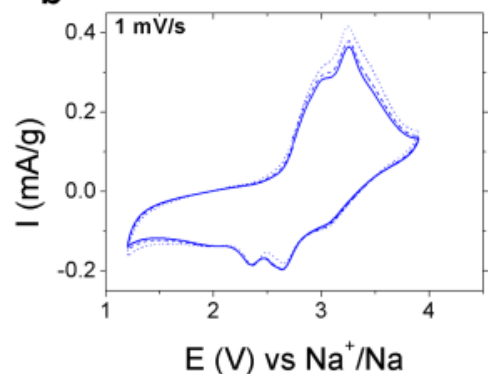

d

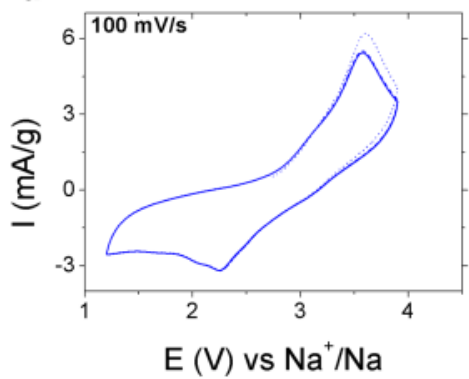

d

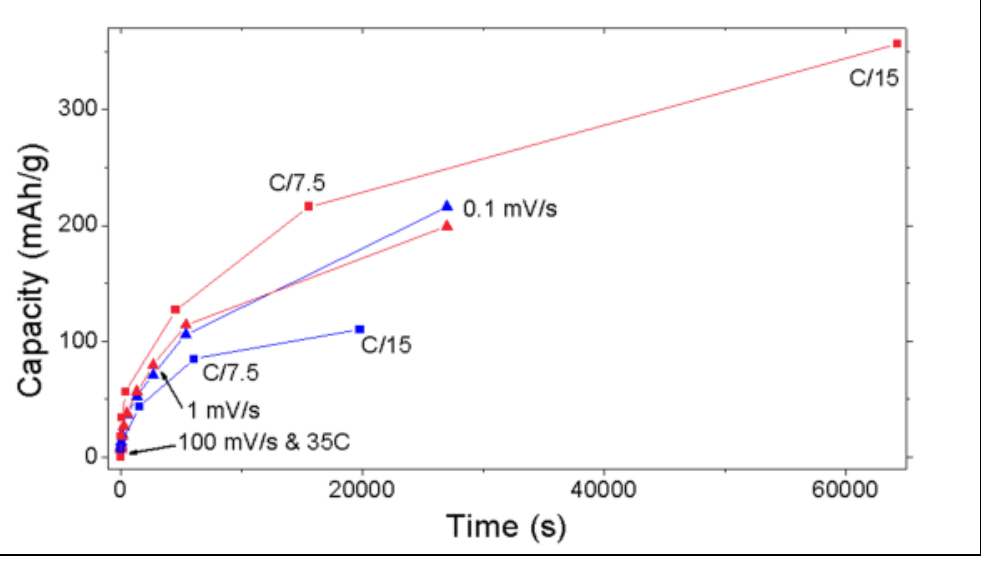

Figure S12. Electrochemical properties of Häggite vs. lithium and sodium insertion. First three cyclic voltammograms vs. lithium $\left(\mathrm{LiClO}_{4} 1 \mathrm{~mol} \cdot \mathrm{L}^{-1}\right.$ in $\mathrm{PC}$ ) at (a) $1 \mathrm{mV} \cdot \mathrm{s}^{-1}$, and (c) $100 \mathrm{mV} \cdot \mathrm{s}^{-1}$. First three cyclic voltammograms vs. sodium $\left(\mathrm{NaClO}_{4} 1 \mathrm{~mol} \cdot \mathrm{L}^{-1}\right.$ in PC) at (b) $1 \mathrm{mV} \cdot \mathrm{s}^{-1}$, and (d) $100 \mathrm{mV} \cdot \mathrm{s}^{-1}$. (e) Specific capacities of Häggite as a function of charging time, for $\mathrm{Li}^{+}$(pink) and $\mathrm{Na}^{+}$(blue) insertions, measured in cyclic voltammetry (triangles) and galvanostatic modes (squares). For both $\mathrm{Li}^{+}$and $\mathrm{Na}^{+}$insertions, redox phenomena are reversible. Moreover, the intensity of reduction waves is proportional to the power 0.65 of the sweep rate. Hence the storage mechanism of Häggite for $\mathrm{Li}$ and $\mathrm{Na}$ cells is mostly faradaic, but shows a non-negligible capacitive contribution ${ }^{54}$. The capacity drops rapidly when the cycling rate is increased, in agreement with the faradaic behavior that implies slow processes. Interestingly, Häggite behaves similarly versus lithium and sodium ions, despite the larger ionic size of the latter, instead of other lamellar phases, e.g. graphitic carbon which does not insert $\mathrm{Na}^{+}$. 

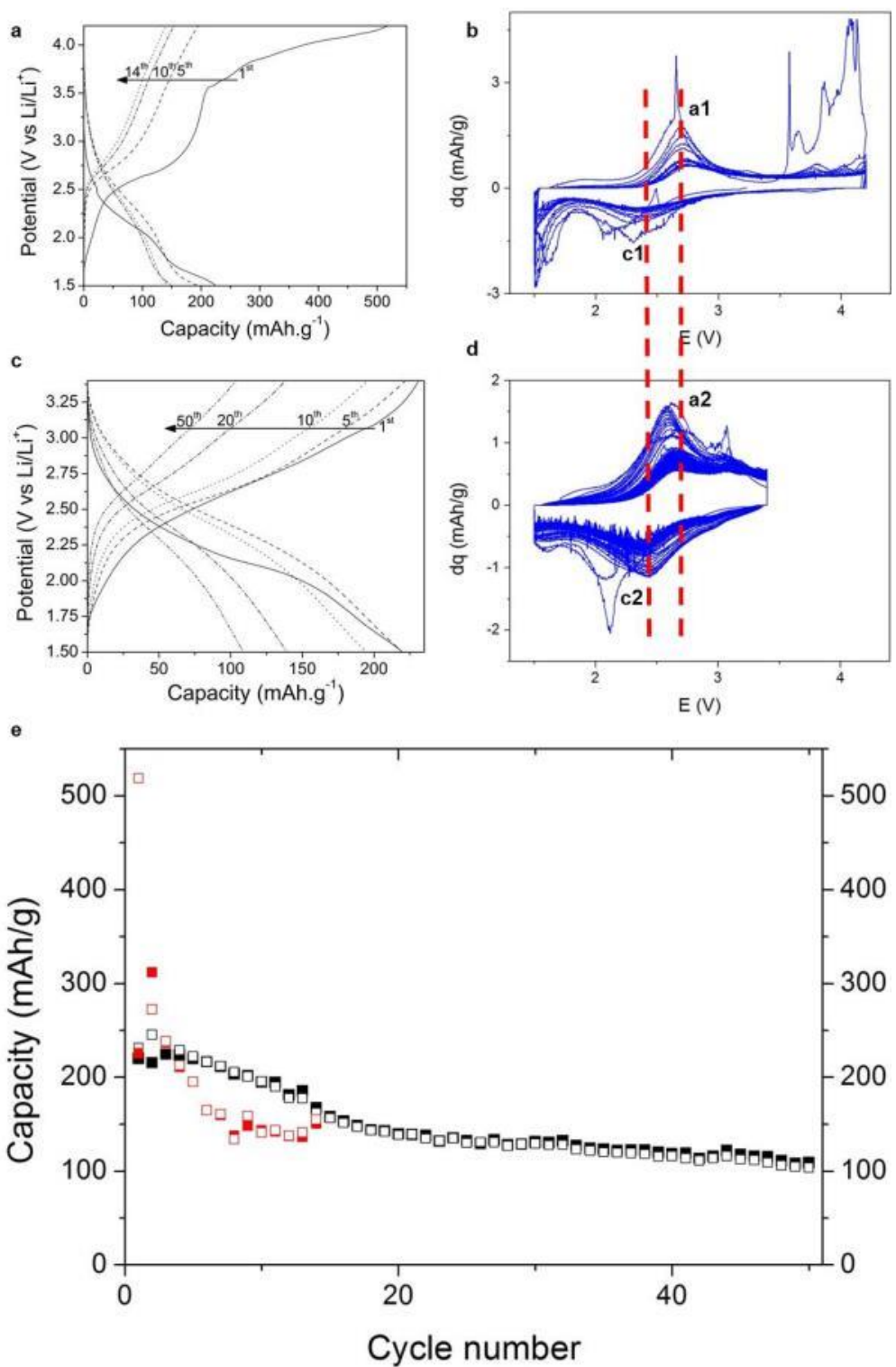

Figure S13. Effect of highest oxidation potential limitation (from 4.2 to $3.4 \mathrm{~V}$ ) on the Häggite-Li (H-Li) battery lifetime. Behaviors upon cycling between 1.5 and (a-b) $4.2 \mathrm{~V}$ or (cd) $3.4 \mathrm{~V} \mathrm{vs} \mathrm{Li}^{+} / \mathrm{Li}$ in LP30 electrolyte. (e) Cycling behavior for both highest potentials $(4.2 \mathrm{~V}$ in red; $3.4 \mathrm{~V}$ in black). When the highest oxidation potential is $4.2 \mathrm{~V} \mathrm{vs} \mathrm{Li}^{+} / \mathrm{Li}$, an irreversible reaction is happening during the first cycle. When this potential is lowered to $3.4 \mathrm{~V} \mathrm{vs}^{+} / \mathrm{Li}$, the corresponding phase transformation is avoided, as shown by the similar aspect of the first cycle and the following ones and by the potential shift of the oxidation wave on the differential representation ( $b$ and $d)$. 
a

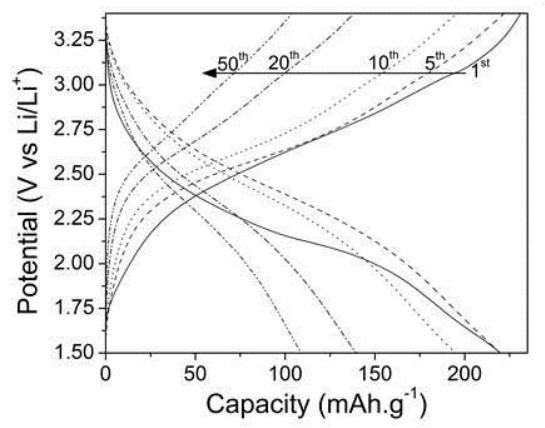

c b

H-Li

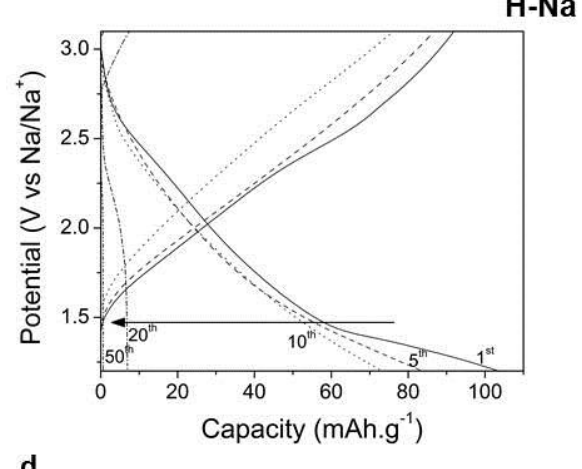

d

D-Li
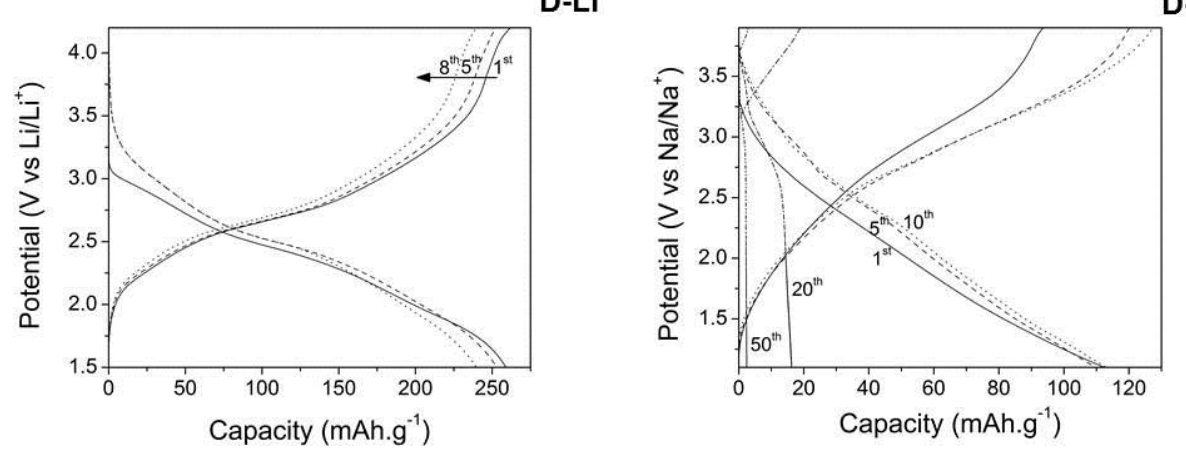

D-Na

Figure S14. Galvanostatic cycles for (a) Häggite versus lithium (H-li) (highest potential of $3.4 \mathrm{~V}$ ), (b) Häggite versus sodium (H-Na), (c) Duttonite versus lithium (D-Li) and (d) Duttonite versus sodium (D-Na). 